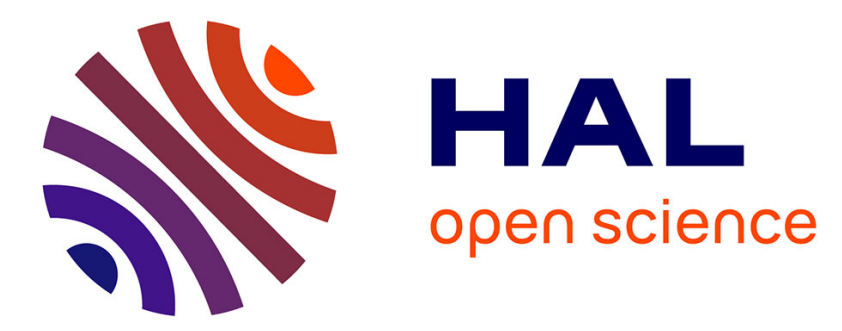

\title{
La Cour suprême au Royaume-Uni après le Constitutional Reform Act 2005: une juridiction hors norme
}

Aurélie Duffy-Meunier

\section{To cite this version:}

Aurélie Duffy-Meunier. La Cour suprême au Royaume-Uni après le Constitutional Reform Act 2005 : une juridiction hors norme. Revue internationale de droit comparé, 2012, 64 (n 3), pp.681 - 734 . 10.3406/ridc.2012.20099 . hal-02610733

\section{HAL Id: hal-02610733 \\ https://hal-amu.archives-ouvertes.fr/hal-02610733}

Submitted on 18 May 2020

HAL is a multi-disciplinary open access archive for the deposit and dissemination of scientific research documents, whether they are published or not. The documents may come from teaching and research institutions in France or abroad, or from public or private research centers.
L'archive ouverte pluridisciplinaire HAL, est destinée au dépôt et à la diffusion de documents scientifiques de niveau recherche, publiés ou non, émanant des établissements d'enseignement et de recherche français ou étrangers, des laboratoires publics ou privés.

\section{(1) (1) $\$$}

Distributed under a Creative Commons Attribution - NonCommercial - NoDerivatives 44.0 


\section{La Cour suprême au Royaume-Uni après le Constitutional} Reform Act 2005 : une juridiction hors norme Aurélie Duffy-Meunier

\section{Citer ce document / Cite this document :}

Duffy-Meunier Aurélie. La Cour suprême au Royaume-Uni après le Constitutional Reform Act 2005 : une juridiction hors norme . In: Revue internationale de droit comparé. Vol. 64 N³,2012. pp. 681-734;

doi : https://doi.org/10.3406/ridc.2012.20099

https://www.persee.fr/doc/ridc_0035-3337_2012_num_64_3_20099

Fichier pdf généré le 09/04/2018 


\title{
Résumé
}

La transformation de l'Appellate Committee de la Chambre des Lords en Cour suprême par le Constitutional Reform Act de 2005 (CRA) bouleverse-t-elle radicalement le constitutionnalisme britannique ou n'est-elle qu'une réforme symbolique ? Novateur par certains aspects, le CRA est, par d'autres caractéristiques, seulement révélateur de ce qui existait déjà à l'époque de l'Appellate Committee de la Chambre des Lords. Cette loi conforte des convergences déjà existantes entre les caractéristiques de la Cour suprême et celles d'autres juridictions, aussi bien suprêmes que constitutionnelles, mais n'a cependant pas effacé la nature atypique de cette juridiction. L'analyse de la Cour suprême conduit ainsi à dépasser la modélisation des systèmes de justice constitutionnelle et révèle la nécessité d'appréhender plus largement cette notion. La révision constitutionnelle introduite par le CRA témoigne donc d'une évolution remarquable de la Constitution du Royaume-Uni qui enrichit le débat sur la notion de justice constitutionnelle et, plus largement, sur le constitutionnalisme.

\begin{abstract}
Is the replacement of the Appellate Committee of The House of Lords with a new Supreme Court for the United Kingdom a radical transformation of British constitutionalism or a symbolic reform ? Some contributions of the CRA are innovative, but this Act also reveals what already existed at the time of the Appellate Committee of the House of Lords. The CRA confirms and increases convergences with the characteristics of other supreme and constitutional courts. However, it has not erased the peculiar nature of this jurisdiction. As a result, the UK's Supreme Court contributes to the renewal of constitutional justice. It goes beyond the traditional models of constitutional justice and reveals the necessity to think more widely about constitutional justice. After all, the CRA has given rise to an outstanding evolution of the United Kingdom's Constitution which enhances the debate on constitutional justice and constitutionalism.
\end{abstract}




\title{
LA COUR SUPRÊME AU ROYAUME-UNI APRÈS LE CONSTITUTIONAL REFORM ACT 2005 : UNE JURIDICTION HORS NORME
}

\author{
Aurélie DUFFY-MEUNIER*
}

La transformation de l'Appellate Committee de la Chambre des Lords en Cour suprême par le Constitutional Reform Act de 2005 (CRA) bouleverse-t-elle radicalement le constitutionnalisme britannique ou n'est-elle qu'une réforme symbolique ? Novateur par certains aspects, le $C R A$ est, par d'autres caractéristiques, seulement révélateur de ce qui existait déjà à l'époque de l'Appellate Committee de la Chambre des Lords. Cette loi conforte des convergences déjà existantes entre les caractéristiques de la Cour suprême et celles d'autres juridictions, aussi bien suprêmes que constitutionnelles, mais n'a cependant pas effacé la nature atypique de cette juridiction. L'analyse de la Cour suprême conduit ainsi à dépasser la modélisation des systèmes de justice constitutionnelle et révèle la nécessité d'appréhender plus largement cette notion. La révision constitutionnelle introduite par le CRA témoigne donc d'une évolution remarquable de la Constitution du Royaume-Uni qui enrichit le débat sur la notion de justice constitutionnelle et, plus largement, sur le constitutionnalisme.

Is the replacement of the Appellate Committee of The House of Lords with a new Supreme Court for the United Kingdom a radical transformation of British constitutionalism or a symbolic reform? Some contributions of the CRA are innovative, but this Act also reveals what already existed at the time of the Appellate Committee of the House of Lords. The CRA confirms and increases convergences with the characteristics of other supreme and constitutional courts. However, it has not erased the peculiar nature of this jurisdiction. As a result, the UK's Supreme Court contributes to the renewal of constitutional justice. It goes beyond the traditional models of constitutional justice and reveals the necessity to think more widely about constitutional justice. After all, the CRA has given rise to an outstanding evolution of the United

* Maître de conférences à l’Université Paris II-Panthéon-Assas, membre de l'Institut de droit comparé, Membre associé à l'Institut Louis Favoreu - Groupe d'études et de recherches sur la justice constitutionnelle, CNRS UMR 6201. 
Kingdom's Constitution which enhances the debate on constitutional justice and constitutionalism.

Le $1^{\text {er }}$ octobre 2009, les onze Justices de la Cour suprême britannique prêtaient serment concrétisant, plus de six ans après son annonce, la mise en place de cette juridiction qui a succédé à l'Appellate Committee de la Chambre des Lords. Cette formation juridictionnelle de la Chambre des Lords siégeait, pour des raisons historiques ${ }^{1}$ et malgré l'adoption de l'Appellate Jurisdiction Act 1876 qui en a professionnalisé la composition ${ }^{2}$, au sein de la Chambre haute du Parlement de Westminster. Ce mélange des genres a conduit le Gouvernement du Premier ministre Blair à vouloir en clarifier le fonctionnement au nom de la séparation des pouvoirs ${ }^{3}$.

La remise en cause de la Chambre des Lords ${ }^{4}$ et sa substitution par une Cour suprême n'est pas une idée nouvelle au Royaume-Uni. En 1790 déjà, Jeremy Bentham écrivait qu'il serait plus sage de «donner la parole à un cheval dans cette Chambre plutôt qu'à un juge » car «le fait de hennir dans la Chambre ne rend pas un cheval plus difficile à monter; mais y siéger et y voter rend un juge moins apte à juger ». Selon lui, cette situation conduit les membres de l'Appellate Committee à « juger en un nom ce qu'ils ont fait en un autre nom $»^{5}$. De même, à la fin du XIX ${ }^{\mathrm{e}}$ siècle, Walter Bagehot considérait que la plus haute juridiction britannique devrait être une juridiction visible qui ne «devrait pas être cachée derrière la robe d'une assemblée législative $»^{6}$.

Dans le prolongement de ces critiques, une loi de 1873, le Supreme Court of Judicature Act, proposée par le Gouvernement libéral de Gladstone

${ }^{1}$ Le cadre limité de cette étude ne nous permet pas de revenir sur l'évolution historique de la formation juridictionnelle de la Chambre des Lords. Nous renvoyons notamment à ce propos à T. BEVEN, « The Appellate jurisdiction of the House of Lords », LQR, 1901, p. 155 ; L. BLOMCOOPER, B. DICKSON et G. DREWRY (dir.), The Judicial House of Lords 1876-2009, Oxford University Press, 2009, pp. 3-29 et 181-275; L. BLOM-COOPER et G. DREWRY, Final Appeal : A Study of the House of Lords in its Judicial Capacity, Clarendon Press, 1972 ; Lord Neuberger of Abbotsbury, Master of the Rolls, "The Supreme Court: is the House of Lords "Losing part of itself'? ", The Young Legal Group of the British Friends of the Hebrew University Lecture, 2 december 2009, pp. 3-6; D. PANNICK, " "Better that a horse should have a voice in the House [of Lords] than that a judge should" (Jeremy Bentham): replacing the Law Lords by a Supreme Court ", $P L, 2009$, pp. 723-728.

${ }^{2}$ Section 5 de 1'Appellate Jurisdiction Act 1876.

${ }^{3}$ Lord Falconer of Thoroton, Secrétaire d'État aux affaires constitutionnelles et Lord Chancelier, Hansard, HL, 9 February, 2004, col. 927.

${ }^{4}$ Par souci de concision, nous utiliserons parfois l'appellation Chambre des Lords pour désigner cette formation juridictionnelle.

${ }^{5}$ J. BENTHAM, «Draft for the Organisation of Judicial Establishments, compared with that of the National Assembly [of France] with a commentary on the Same (1790)», in J. BOWRINNNG (ed.), The Works of Jeremy Bentham, vol. 4, p. 381.

${ }^{6}$ W. BAGEHOT, The English Constitution, 1867, Londres, Chapman and Hall, p. 157. 
a envisagé de supprimer les compétences d'appel de la Chambre des Lords lui substituant une nouvelle Cour suprême pour l'Angleterre et le pays de Galles, composée de la Haute Cour et de la Cour d'appel. Cependant, le Gouvernement conservateur de Disraeli arrivé au pouvoir en 1874 revint sur ce projet en faisant voter l'Appellate Jurisdiction Act 1876 qui a rétabli la Chambre des Lords sous sa forme moderne avant que la loi de 1873 ne produise ses effets ${ }^{7}$.

Des critiques plus récemment formulées par des organisations non gouvernementales ou par certains membres de l'Appellate Committee de la Chambre des Lords eux-mêmes ${ }^{8}$ font écho à la position de ces deux grands juristes. En 1999, l'organisation Justice a, à la demande de la Commission Royale sur la réforme de la Chambre des Lords, formulé plusieurs propositions au nombre desquelles on trouve l'institution d'une Cour suprême indépendante. Certains éléments contenus dans cette proposition ont été repris par le Gouvernement dans son propre projet ${ }^{9}$. Par ailleurs, dès 2001, Lord Bingham, Président de la Chambre des Lords et Lord Steyn ${ }^{10}$, sont intervenus à plusieurs reprises en faveur de l'instauration d'une Cour suprême, mais se sont heurtés au Lord Chancelier de l'époque, Lord Irvine of Lairg ${ }^{11}$. Certaines Commissions parlementaires se sont également rangées aux vues avancées par Lord Bingham en proposant le départ des Law Lords de la formation parlementaire de la Chambre des Lords ${ }^{12}$. Malgré l'opposition du Lord Chancelier et à la plus grande surprise de tous ${ }^{13}$, ces

7 À ce propos, cf. D. STEELE, «The Judicial House of Lords : Abolition and Restoration 1873-6 », in L. BLOM-COOPER, B. DICKSON et G. DREWRY (dir.), The Judicial House of Lords 1876-2009, op. cit., pp. 13-29.

${ }^{8}$ La contribution des Lords of Appeal in ordinary au travail de la Chambre avant la mise en place de la Cour suprême a été discutée au sein même de la Chambre Cf. Hansard, HL, July 21, 2009, col. 712 et col. 1507.

9 Justice, "The judicial functions of the House of Lords », Written Evidence to the Royal Commission on the Reform of the House of Lords, 19 may 1999, disponible sur le site: www.justice.org.uk Cf. également la contribution du projet du University College London Constitution Unit, A. Le SUEUR et R. CORNES, The Future of the UK's Highest Courts, Londres, UCL Constitution Unit, 2001.

${ }^{10}$ Entretien de Lord Bingham of Cornhill, " The supreme sacrifice », The Times, 17 July 2001 ; «A new Supreme Court for the United Kingdom», The Constitution Unit Spring Lecture 2002, 1rst may 2002, disponible sur www.ucl.ac.uk/spp/publications/unit-publications/90.pdf p. 9 ; " The Evolving Constitution », EHRLR, 2002, pp. 1-16 et Lord Steyn, " The Case for a Supreme Court », LQR, 2002, p. 382.

11 A ce propos, cf. Lord Hope, "The role of the Law Lords' sub-committee in the development of the UK Supreme Court », United Kingdom Supreme Court conference, Law Society, 17 november 2008, disponible sur http://www.justice.gov.uk/about/supreme-court-conference-hopespeech.htm.

${ }^{12}$ House of Commons Public Administration Select Committee, The Second Chamber: Continuing the Reform, $5^{\text {th }}$ report of 2001-02, HC 494, 12 February 2002, § 153.

${ }^{13}$ Aे ce propos, cf. Lord Phillips of Worth Matravers, «The Challenges of the Supreme Court », The Gresham Special Lecture 2010, 8 June 2010 et Lord Clark, « The supreme Court-One year on », Bracton Law Lecture, Exeter University 11 november 2010, p. 8. 
réflexions et propositions se sont concrétisées quelques années plus tard à l'occasion de l'annonce d'un remaniement ministériel par le Premier ministre Tony Blair dans un simple communiqué de presse le 12 juin $2003^{14}$. La décision du Gouvernement a fait grand bruit en raison notamment de la méthode employée.

Sur la forme, la mise en place d'une Cour suprême au Royaume-Uni a été présentée avec d'autres réformes constitutionnelles d'envergure au nombre desquelles on trouve l'abolition de la fonction de Lord Chancelier qui était à la fois membre du Gouvernement et Président de la Chambre des Lords dans ses formations parlementaire et juridictionnelle ${ }^{15}$, la modification de la fonction de Speaker à la Chambre des Lords et de nouvelles modalités de désignation des juges. Compte tenu de leur ampleur, la présentation de ces réformes évoquées au détour de l'annonce d'un remaniement ministériel comportant le remplacement du Lord Chancelier, Lord Irvine, par le Premier ministre - qui n'avait même pas consulté son cabinet - a été particulièrement critiquée $^{16}$. S'est ajouté à ce remplacement une refonte de l'organisation du Ministère du Lord Chancelier (Lord Chancellor's Department) et sa transformation en Ministère des affaires constitutionnelles chargé de piloter une réforme à laquelle l'ancien Lord Chancelier s'était opposé ${ }^{17}$. Prenant le prétexte qu'il n'avait pas été informé par le Premier ministre ${ }^{18}$, Lord Irvine a

${ }^{14}$ Modenising Governement-Lord Falconer appointed Secretary of State for Constitutional Affaires, 12 june 2003, disponible sur http://www.number10.gov.uk/output/Page3892.asp. Sur la préparation du Constitutional Reform Act 2005. Cf. C. de BEAUSSE de la HOUGUE, «Un aspect des réformes constitutionnelles au Royaume-Uni : La disparition du Lord Chancelier. D'une Constitution non écrite vers une Constitution écrite ? », RFDC, $\mathrm{n}^{\circ}$ 62, 2005, pp. 291-309; J. BELL, « Droit constitutionnel étranger : L'actualité constitutionnelle dans les pays de common law et de droit mixte ; Royaume-Uni », Chroniques, RFDC, $\mathrm{n}^{\circ} 57,2004$, pp. 152-158 ; A. Le SUEUR, « New Labour's next (suprisingly quick) Steps in Constitutional Reform », PL, 2003, pp. 368-377; "The Conception of the UK's New Supreme Court», in A. Le SUEUR (ed.), Building the UK's New Supreme Court: National and Comparative Perspectives, Oxford University Press, 2004, pp. 3-20 et "From Appellate Committee to Supreme Court: A Narrative», in L. BLOM-COOPER, B. DICKSON et G. DREWRY (dir.), The Judicial House of Lords 1876-2009, op. cit., pp. 64-94; Lord Windlesham, «The Constitutional Reform Act 2005: Ministers, Judges and Constitutional Change : Part I », PL, 2005, pp. 806-823; House of Commons Constitutional affairs Committee, Constitutional Reform Bill [Lords]: the Government's proposals, Third Report, HC 275-I, HC 275II, 28 January 2005.

${ }^{15} \mathrm{La}$ loi a finalement dissocié les différentes casquettes du Lord Chancelier. Nous nous permettons de renvoyer à ce sujet à notre chronique, "Droit constitutionnel étranger : l'actualité constitutionnelle dans les pays de common law et de droit mixte; Royaume-Uni », Chronique, $R F D C, 2006, \mathrm{n}^{\circ} 66$, pp. 399-403.

${ }^{16}$ R. MASTERMAN, «A Supreme Court for the United Kingdom : Two Steps Forward, but one Step Back on Judicial Independence », PL, 2004, p. 51.

${ }^{17}$ Hansard, HL, 10 June 2002, col. 3WA.

${ }^{18}$ Lord Irvine, finalement disposé à conduire les consultations en vue de ces réformes aurait démissionné en raison du refus du Premier ministre. À ce propos, cf. le memorandum du 26 octobre 2009 de Lord Irvine of Lairg et la lettre de Tony Blair du 18 décembre 2009 devant le House of 
démissionné de ses fonctions. On peut regretter ce processus de prise de décision sans consultation préalable des membres du pouvoir judiciaire, que le Premier ministre lui-même a qualifié a posteriori de "chaotique » et « désordonnée » ${ }^{19}$.

L'annonce de ces réformes a divisé le monde judiciaire ${ }^{20}$. Alors que Lord Bingham of Cornhill défendait ardemment la mise en place d'une Cour suprême, cette idée a suscité les craintes du Lord Chief Justice, Lord Woolf, du Vice-Lord Chief Justice, Lord Judge, et du Conseil des juges (Judges Council) en raison de l'atteinte qu'elle serait susceptible de porter à l'indépendance du pouvoir judiciaire ${ }^{21}$. Pour calmer ces critiques une consultation a été réalisée a posteriori. Elle a permis la conclusion d'un Concordat $^{22}$ entre le Lord Chancelier et le Lord Chief Justice qui fût un facteur d'apaisement. Le projet de loi a finalement été déposé devant la Chambre des Lords le 24 février 2004, après avoir été présenté par une déclaration ministérielle du nouveau Lord Chancelier, Lord Falconer of Thorothon $^{23}$. Il a, chose rare, été examiné par une Commission spéciale : le Select Committee on the Constitutional Reform Bill ${ }^{24}$. Le Constitutional Reform Act 2005 (CRA) a finalement été promulgué le 24 mars 2005, mais son entrée en vigueur s'est échelonnée dans le temps. Les dispositions concernant le Lord Chancelier, les modalités de nomination des juges sont

Lords Constitution Select Committee, Constitution Committee, Fourth Report, The Cabinet Office and the Centre of Government, Minutes of Evidence, 29 January 2010, HL, 30.

${ }^{19}$ Lettre de Tony Blair du 18 décembre 2009 devant le House of Lords Constitution Select Committee, Constitution Committee, Fourth Report, The Cabinet Office and the Centre of Government, Minutes of Evidence, 29 January 2010, HL, 30.

${ }^{20}$ Il apparaît un partage de position assez égalitaire au sein des Law Lords puisque cinq d'entre eux étaient contre, cinq y étaient favorables, un Law Lord s'est abstenu et le dernier n'avait pas encore d'avis tranché sur la question. Sur cette division, cf. C. FAIRBAIRN et S. BROADBRIDGE, Home Affairs Section, House of Common Library, "The Constitutional Reform Bill [HL] : a Supreme Court for the United Kingdom and judicial appointments Bill », No 18 of 2004-05, Research paper 05/06, 13 January 2005, p. 28 disponible sur http://www.parliament.uk/documents/commons/lib/research/rp2005/rp05-006.pdf.

${ }^{21}$ Lord Windlesham, «The Constitutional Reform Act 2005: Ministers, Judges and Constitutional Change, Part I », op. cit., p. 811 et 815.

${ }^{22}$ The Lord Chancellor's Judiciary-Related Functions : Proposals ; House of Lords, Report of the Select Committe on the Constitutional Reform Bill, 26 January 2004, [HL], Session 2003-2004, HL Paper 125, pp. 202-224 (Appendix 6).

${ }^{23}$ Lord Falconer of Thoroton, Secretary of State for Constitutional Affairs and Lord Chancelor, Hansard, HL, 9 February, 2004, col. 927.

24 Select Committee on the Constitutional Reform Bill, Constitutional Reform Bill, First Report, HL 125-I, HL 125-II, 2 July 2004. Cf. à propos du détail de l'élaboration de ce projet de loi, A. Le SUEUR, "From Appellate Committee to Supreme Court: A Narrative », in L. BLOMCOOPER, B. DICKSON et G. DREWRY (dir.), The Judicial House of Lords 1876-2009, op. cit., pp. 64-94. 
entrées en vigueur le 3 avril $2006^{25}$. En revanche, l'entrée en fonction de la Cour suprême, conditionnée au terme d'une clause suspensive par les locaux dans lesquels elle pourrait s'établir, a eu lieu le $1^{\text {er }}$ octobre $2009^{26}$.

Sur le fond, le projet du Gouvernement a été motivé par une volonté de «moderniser et de redéfinir les relations entre les pouvoirs exécutif, législatif et judiciaire », de " protéger et ainsi de renforcer l'indépendance du pouvoir judiciaire, de clarifier le rôle du Gouvernement et du pouvoir judiciaire et d'instaurer des relations sur une base explicite et transparente ${ }^{27}$. En dépit de ces arguments, la création d'une Cour suprême ne faisait à l'origine pas partie des priorités initiales du Gouvernement et a davantage résulté de l'effet d'entraînement de l'abolition du Lord Chancelier plutôt que d'une volonté politique forte de réformer cette institution ${ }^{28}$. C'est au mois de janvier 2004 que Lord Falconer of Thoroton a annoncé «qu'il était temps que la plus haute juridiction britannique se dégage de l'ombre du pouvoir législatif $»^{29}$. Il s'agissait, en réalité, d'améliorer la perception que l'opinion publique pouvait avoir d'une formation juridictionnelle de la Chambre des Lords faisant partie intégrante de la Chambre législative. C'est surtout la perspective d'une condamnation de la Cour européenne des droits de l'Homme (CourEDH) qui a accéléré la remise en cause de la Haute juridiction britannique. L'affaire McGonnel $c$. Royaume-Uni $i^{30}$ pouvait laisser présager un risque de condamnation du fait de la position particulière des Law Lords ayant des fonctions à la fois législatives et judiciaires ${ }^{31}$. D'ailleurs, la Commission des droits de l'Homme et des affaires juridiques de l'Assemblée parlementaire du Conseil de l'Europe avait adopté un rapport au mois d'avril 2003 concernant la

${ }^{25}$ Pour le détail de l'entrée en vigueur de l'ensemble des dispositions, cf. House of Lords Select Committee on the Constitution, Constitutional Reform Act 2005, 5th Report, HL 83, 13 december 2005, p. 7.

${ }^{26}$ Section $148(4)(5)$ du $C R A$.

${ }^{27}$ Lord Falconer, Hansard, HL, 12 February 2004 col. 1213.

${ }^{28}$ Lord Phillips of Worth Matravers, «The Challenges of the Supreme Court », The Gresham Special Lecture, 2010, 8 june 2010, p. 5 disponible sur le site de la Cour suprême: http://www.supremecourt.gov.uk.

${ }^{29}$ Hansard, HL, Vol. 657, col. 26, 26 January, 2004.

${ }^{30}$ CourEDH, 8 févr. 2000, McGonnel c. Royaume-Uni, req. 28488/95. Dans cette décision, la Cour européenne des droits de l'homme a condamné le Royaume-Uni pour violation de l'article 6-1 $\mathrm{CEDH}$ en raison des fonctions à la fois législative et judiciaire du Bailli de Guernesey. La Cour estimant que « toute participation directe à l'adoption de textes législatifs ou réglementaires peut suffire à jeter le doute sur l'impartialité judiciaire d'une personne amenée ultérieurement à trancher un différend sur le point de savoir s'il existe des motifs justifiant que l'on s'écarte du libellé des textes législatifs ou réglementaires en question », $\S 55$.

31 À ce propos, cf. not. A. ANTOINE, «Les enjeux de la création d'une Cour suprême au Royaume-Uni et la Convention européenne des droits de l'homme et des libertés fondamentales », RIDC, $\mathrm{n}^{\circ}$ 2, 2008, pp. 283-291 ; Lord Hope of Craighead, "The Reform of the House of Lords ", $R I D C, \mathrm{n}^{\circ} 2,2008$, pp. 259-262. 
fonction de Lord Chancelier dans le système constitutionnel du RoyaumeUni. Il comportait des recommandations suggérant aux autorités britanniques la création d'une Cour suprême dont les membres ne seraient pas à la fois juges de la plus haute juridiction et membres de l'Assemblée parlementaire ${ }^{32}$. La réforme aurait donc pu se limiter à une simple interdiction pour les Law Lords de participer aux débats parlementaires et à leur maintien au sein d'une Commission de la Chambre des Lords. L'importance des apparences ${ }^{33}$ exigeant d'aller au bout de la logique, le $C R A$ a choisi l'option radicale en établissant une Cour suprême séparant les formations juridictionnelle et parlementaire de la Chambre des Lords.

À ces avancées concrètes s'ajoute un apport, plus théorique, mais tout aussi remarquable du CRA qui permet de situer l'instauration de la Cour suprême britannique au sein d'un contexte constitutionnel en pleine mutation. Il est fait référence, pour la première fois dans un texte de loi, au principe de Rule of Law, qui constitue avec la souveraineté du Parlement l'un des deux fondements de la Constitution britannique. Le principe de Rule of Law, traduit par l'expression « la suprématie ou le règne de la loi » ${ }^{34}$ ou «prééminence du droit » ${ }^{35}$ recouvre, tel qu'il a été défini par Albert V. Dicey, trois aspects distincts : un principe de légalité, un principe d'égalité de tous devant le droit $^{36}$ et un principe de «protection judiciaire des droits $»^{37}$. Cette consécration textuelle de la Rule of Law, sur laquelle nous reviendrons, s'inscrit dans un mouvement de rééquilibrage des fondements constitutionnels britanniques en faveur de ce principe. Les deux piliers du cadre constitutionnel britannique font, depuis un certain temps déjà, l'objet

${ }^{32}$ Commitee on Legal Affairs and Human Rights, Office of the Lord Chancellor in the Constitutional System of the United Kingdom, 28 april 2003, Doc. 9798. Document disponible sur http://assembly.coe.int/Documents/WorkingDocs/doc03/EDOC9798.htm.

${ }^{33}$ F. SUDRE, «Le mystère des apparences dans la jurisprudence de la Cour européenne des droits de l'homme », RTDH, 2009, n 79, p. 633.

${ }^{34} \mathrm{Cf}$. la traduction d'André Batut et de Gaston Jèze de A. V. DICEY, Introduction à l'étude du droit constitutionnel, Paris, Girard \& Brière, 1902, p. 167.

${ }^{35}$ Statut du Conseil de l'Europe, Londres, 5 mai 1949.

${ }^{36}$ Le principe de légalité désigne « la suprématie absolue ou prédominance de la loi opposée à l'influence du pouvoir arbitraire». Le principe d'égalité correspond à la «sujétion égale de toutes les classes à la loi ordinaire du pays, administrée par les tribunaux ordinaires de droit ». Ce principe « exclut l'idée de toute exemption des fonctionnaires ou autres de l'obligation d'obéissance à la loi qui régit les autres citoyens ou de la juridiction des tribunaux ordinaires ». Cf. A. V. DICEY, Introduction à l'étude du droit constitutionnel, op. cit., p. 180.

${ }^{37}$ Le principe de «protection judiciaire des droits » (expression empruntée au professeur E. ZOLLER, in Introduction au droit public, op. cit., p. 101) signifie que « la Rule of Law traverse toute la constitution dans la mesure où ses principes généraux (comme, par exemple, la liberté individuelle, ou le droit de réunion) dérivent chez nous des décisions des cours de justice qui, au gré des cas d'espèce portés devant elles, fixent les droits des personnes privées, alors que dans beaucoup d'autres pays, la seule garantie des droits des individus découle ou semble découler des principes généraux de la Constitution ». A. V. DICEY, Introduction à l'étude du droit constitutionnel, Paris, Girard \& Brière, 1902, p. 174. 
d'importantes évolutions. La réalité du principe de souveraineté parlementaire ne correspond plus aujourd'hui au tableau dépeint par Albert A. V. Dicey qui en faisait le premier principe du droit public anglais. L'impossibilité pour le Parlement de lier ses successeurs, l'interdiction faite à toute personne ou à tout corps d'annuler ou d'écarter une loi et l'absence de distinction entre lois ordinaires et constitutionnelles qui sont les trois composantes de la souveraineté parlementaire $^{38}$ sont aujourd'hui remises en cause, à des degrés différents, par l'adhésion du Royaume-Uni au cadre européen communautaire - aujourd'hui de l'Union européenne - avec le European Communities Act 1972 (EC Act 1972) et conventionnel avec le Human Rights Act 1998 (HRA 1998). L'institution de la nouvelle Cour suprême s'inscrit donc dans un mouvement général de transformation de la Constitution britannique ${ }^{39}$ qui résulte de la mutation de ses deux fondements et de son écriture progressive par un nombre croissant de lois matériellement constitutionnelles ${ }^{40}$. Le $C R A$ a révisé, à l'instar de ces lois, la Constitution souple du Royaume-Uni.

Quelle est, en conséquence, la portée de cette loi sur la plus Haute juridiction du Royaume-Uni désormais dénommée Cour suprême ? Dans quelle mesure cette juridiction peut-elle être qualifiée de Cour suprême alors même que cette appellation peut recouvrir des réalités différentes ? Cette réforme a été présentée comme « un changement sur le plan de la forme, et

${ }^{38}$ A. V. DICEY, Introduction à l'étude du droit constitutionnel, op. cit., pp. 78-82. Dicey considère que ce principe donne au Parlement « le droit de faire ou de défaire n'importe quelle loi, quelle qu'elle soit; il signifie, de plus, que la loi anglaise ne reconnaît à aucun homme, ni aucun corps, le droit de négliger ou d'écarter les lois faites par le Parlement », p. 36. Dicey résume les trois aspects du principe de souveraineté parlementaire de la façon suivante: "Voici donc les trois éléments de la Souveraineté parlementaire, telle qu'elle existe en Angleterre : $1^{\circ}$ pouvoir de la législature de modifier librement toute loi ; fondamentale ou non, de la même façon que toute autre loi ; - $2^{\circ}$ absence de toute distinction légale entre les lois constitutionnelles et les autres lois ; - $3^{\circ}$ absence de toute autorité judiciaire ou autre ayant le droit d'annuler un Act du Parlement », p. 81. Pour une présentation éclairante de ce principe, cf. E. ZOLLER, Introduction au droit public, op. cit., pp. 80-95.

${ }^{39}$ Nous nous contenterons d'en retracer les traits les plus marquants. Pour le détail de ces transformations du droit constitutionnel britannique, cf. à propos du principe de souveraineté parlementaire, I. NGUYÊN-DUY, La souveraineté du Parlement britannique, Paris, L'Harmattan, 2011 ; cf. à propos de la dévolution, F. ROUX, La dévolution en Grande-Bretagne, Contribution à la réflexion sur l'autonomie institutionnelle, Paris, Dalloz, 2009 ; cf. à propos de l'appartenance du Royaume-Uni à l'Union européenne, R. WASS-NOCQUET, Le Royaume-Uni : État membre de l'Union européenne - La volonté politique saisie par l'œuvre juridictionnelle, "Collection de la Faculté de droit et des sciences sociales de Poitiers », Paris, LGDJ, 2010. Nous nous permettons de renvoyer à notre thèse à propos du HRA, A. DUFFY, La protection des droits et libertés au Royaume-Uni; Recherche sur le Human Rights Act 1998 et les mutations du droit constitutionnel britannique face aux exigences de la Convention européenne des droits de l'homme, coll. « Fondation Varenne », Paris, LGDJ, 2007.

${ }^{40}$ Ces lois sont la Magna Carta 1215, 1'Act of Settlement 1701, le Petition of Rights 1628, le Bill of Rights 1688, les Acts of Union 1707, les Parliament Acts de 1911 et de 1949 ou, plus récemment, le EC Act 1972, les lois de dévolution de 1998 et le HRA 1998. 
non du fond $»^{41}$. Fidèles au pragmatisme britannique, les dispositions de la troisième partie du $C R A$ dédiée à la Cour suprême concernent essentiellement la désignation et le statut des membres de la Cour, la composition des formations de jugement, les modalités d'adoption des règles de procédure, le statut du personnel et les frais de justice. Les aspects concernant la compétence de la Cour et ses rapports avec les autres juridictions ne constituent qu'une part résiduelle du texte de loi ${ }^{42}$. Les principales préoccupations au cours des débats ont ainsi davantage concerné des aspects pratiques tels que l'emplacement ${ }^{43}$ et le coût ${ }^{44}$ occasionné par l'établissement de la nouvelle Cour suprême plutôt que la question de ses compétences et de sa véritable nature ${ }^{45}$. Les préoccupations qui ont sous-tendu l'élaboration du $C R A$ laissent entendre qu'il n'était pas question pour le Gouvernement de créer une nouvelle institution $^{46}$.

Pourtant, la dénomination de la Cour suprême du Royaume-Uni ne peut empêcher les observateurs étrangers notamment, de penser à la Cour suprême américaine ${ }^{47}$. Les débats parlementaires sont pourtant assez clairs à ce sujet. Lord Falconer, le ministre des Affaires Constitutionnelles a nié avoir été influencé par le modèle de la Cour suprême américaine ${ }^{48}$ et a bien précisé dans le Consultation paper précédant le dépôt du projet de loi qu'il

\footnotetext{
${ }^{41}$ Lord Phillips of Worth Matravers, « La Constitution du Royaume-Uni », CCC, hors série, cinquantenaire du Conseil constitutionnel, 2009, p. 85.

${ }^{42}$ Il s'agit des sections 40 et 41 du $C R A$, alors que les autres aspects sont prévus par les sections 23 à 60 de la loi.

${ }^{43} \mathrm{Cf}$. à ce propos, C. FAIRBAIRN et S. BROADBRIDGE, Home Affairs Section, House of Common Library, «The Constitutional Reform Bill [HL] : a Supreme Court for the United Kingdom and judicial appointments Bill», No 18 of 2004-05, Research paper 05/06, 13 January 2005, op. cit., pp. 41-42; House of Commons Constitutional Affairs Committee, Judicial appointments and a Supreme Court (court of final appeal), First Report, HC 48-1, 10 February 2004, §§ 103-112; House of Commons Constitutional Affairs Committee, Constitutional Reform Bill [Lords]: the Government's proposals, Third Report, HC 275-I, 28 January 2005, §§. 55-59 ; Select Committee on the Constitutional Reform Bill, Constitutional Reform Bill, First Report, HL 125-I, HL 125-II, 2 July 2004, § 439-440 ; Lord Lester of Herne Hill, Hansard, HL, 12 February 2004 col. 1227. En témoigne également la publication d'un ouvrage, C. MIELE (ed.), The Supreme Court of the United Kingdom: History, Art, Architecture, Merrell Publishers, 2010.

${ }^{44}$ Cf., par ex., Lord Woolf, Hansard, HL, 12 February 2004, co1. 293 et Lord Hope of Craighead, Hansard HL, 12 February 2004, co1. 301.

${ }^{45}$ Le SUEUR, «New Labour's next (suprisingly quick) steps in constitutional reform », op. cit., p. 371 ; Lord Hope, "The Role of the Law Lords' sub-committee in the development of the UK Supreme Court », United Kingdom Supreme Court conference, Law Society, 17 november 2008, disponible sur http://www.justice.gov.uk/about/supreme-court-conference-hope-speech.htm.

${ }^{46}$ Lord Hope of Craighead, «The Creation of the Supreme Court - Was it worth it?», Barnard's Inn Reading, 24 June 2010, p. 5.

${ }^{47}$ Cf. par ex. J.-P. DUPRAT, « Le modèle de la cour suprême américaine dans les réformes constitutionnelles actuelles en Grande-Bretagne », in Le renouveau du droit constitutionnel, Mélanges en l'honneur de Louis Favoreu, Paris, Dalloz, 2007, p. 131.

${ }^{48}$ Lord Windlesham, "The Constitutional Reform Act 2005: the Politics of Constitutional Reform, part II », PL, 2006, p. 36.
} 
« n'y a pas de proposition de création d'une Cour suprême sur le modèle américain dotée du pouvoir de renverser une loi. Il n'y a pas non plus de proposition de création d'une Cour constitutionnelle spécialisée ou d'une Cour dont le premier rôle serait de se prononcer a priori sur une question de droit soulevant des difficultés ${ }^{49}$. L'idée d'une Cour suprême à l'américaine ou d'une Cour constitutionnelle spécialisée a été clairement rejetée par le Département des affaires constitutionnelles car cela constituerait une « rupture avec les traditions constitutionnelles britanniques $»^{50}$.

La Cour suprême ne se serait donc inspirée d'aucun modèle préexistant. Cette réforme aurait-elle alors fait "beaucoup de bruit pour rien»? N'aurait-elle qu'une portée symbolique pour ne pas dire cosmétique qui ne serait, pour l'Appellate Committee de Chambre des Lords, qu'une opération de chirurgie esthétique, masquant sous de nouvelles apparences ce qui existait déjà ou réalise-t-elle un changement plus profond? En définitive, quelle réalité se cache-t-il sous cette nouvelle dénomination?

Aux États-Unis la Cour suprême est «la plus haute juridiction du pouvoir judiciaire fédéral ». Le professeur Élisabeth Zoller rappelle qu'elle est «juge en dernier ressort du droit fédéral [qui] ... comprend la Constitution, les traités passés par les États-Unis et les lois du Congrès $»^{51}$. De façon plus générale, les Cours suprêmes ont été présentées par le professeur Louis Favoreu, par opposition aux Cours constitutionnelles selon une conception, qualifiée par certains auteurs de « restrictive $»^{52}$. Elles sont présentées comme «des juridictions placées au sommet de l'édifice juridictionnel d'un État et dont relève par la voie de l'appel ou de la cassation l'ensemble des tribunaux et cours composant cet édifice» qui disposent d'une «vocation générale $»^{53}$ lui permettant de connaitre d'une diversité de contentieux (civil, administratif, pénal...) parmi lesquels on trouve notamment le contentieux constitutionnel. Une Cour suprême se distingue d'une Cour constitutionnelle en ce que cette dernière est une juridiction «créée pour connaître spécialement et exclusivement du contentieux constitutionnel, située hors de l'appareil juridictionnel ordinaire

\footnotetext{
${ }^{49}$ Department for Constitutional Affairs Consultation Paper, Constitutional Reform: A Supreme Court for the United Kingdom, CP11/03, July 2003. disponible sur le site :

http://webarchive.nationalarchives.gov.uk/+http://www.dca.gov.uk/consult/supremecourt/ind ex.htm\#ch3.

${ }^{50}$ Ibid., $\S 23$.

${ }^{51}$ E. ZOLLER, Les Grands arrêts de la Cour suprême des États-Unis, Dalloz, 2010, p. V.

${ }^{52}$ A. Le DIVELLEC et M. de VILLIERS, Dictionnaire de droit constitutionnel, $8^{\text {ème }}$ éd., Paris, Sirey, 2011, p. 97 et p. 101.

${ }^{53}$ L. FAVOREU, "Cours suprêmes et Cours constitutionnelles», in L. CADIET (dir.), Dictionnaire de la Justice, Paris, PUF, 2004, p. 277.
} 
et indépendante de celui-ci comme des pouvoirs publics ${ }^{54}$. La Cour suprême a encore été définie par le professeur Roland Drago comme « une juridiction supérieure unique impliquant l'existence d'un seul ordre juridique et juridictionnel ; [...] une juridiction supérieure statuant en droit et en fait ; [...] une juridiction supérieure pouvant, même indirectement, se prononcer sur des questions constitutionnelles $»{ }^{55}$. Une étude comparative conduite en 1978 met en évidence que «La mission essentielle unanimement reconnue à une cour suprême est de veiller à la bonne application des règles juridiques par les juridictions inférieures et, par làmême, d'assurer au droit unité, clarté, certitude ${ }^{56}$.

Les Cours suprêmes seraient ainsi caractérisées par leur compétence générale et non spécialisée dans le contentieux constitutionnel, par leur place au sommet d'une hiérarchie de juridictions et par leur mission consistant à assurer une certaine «cohérence dans l'application du droit ${ }^{57}$ par les juridictions inférieures. Par contre, si l'on s'en tient aux compétences de ces juridictions, la frontière entre Cours suprêmes et Cours constitutionnelles, n'est pas si étanche puisqu'elles peuvent toutes deux disposer de compétences constitutionnelles $^{58}$. Les auteurs britanniques parlent d'ailleurs de «Cour suprême constitutionnelle ${ }^{59}$. Ainsi, les Cours disposant, comme aux ÉtatsUnis, au Canada ou encore en Inde pour ne se limiter qu'à quelques exemples, d'une plénitude de juridiction et compétentes à ce titre pour le contentieux

${ }^{54}$ L. FAVOREU et W. MASTOR, Les Cours constitutionnelles, coll. «Connaissance du droit», Paris, Dalloz, 2011, pp. 3-4. Cf. également la définition très proche donnée par L. FAVOREU, « Cours suprêmes et Cours constitutionnelles », op. cit., p. 277.

${ }^{55}$ R. DRAGO, « La Cour de cassation, Cour suprême », in L'image doctrinale de la Cour de cassation, La documentation française, 1994, p. 20

${ }^{56}$ A. TUNC, "La cour suprême idéale », La cour judiciaire suprême. Enquête comparative, RIDC, $\mathrm{n}^{\circ} 1-1978$, pp. 435-436.

${ }^{57}$ S. GUINCHARD et T. DEBAR (dir.), Lexique des termes juridiques 2012, $19^{\mathrm{e}}$ éd., Dalloz, 2011 , p. 253.

${ }^{58}$ Des juridictions telles le Conseil d'État ou la Cour de cassation, bien qu'elles refusent toujours de contrôler la constitutionnalité des lois ne sont pas pour autant privées de compétences constitutionnelles notamment, pour ne citer que quelques exemples, dans le cadre du contrôle de l'abrogation implicite des normes anté-constitutionnelles, du contrôle de constitutionnalité des actes juridiques - administratifs, privés et juridictionnels ou encore du filtrage opéré pour renvoyer des questions prioritaires de constitutionnalités comme l'indique bien G. TUSSEAU, Contre les "modèles » de Justice constitutionnelle : essai de critique méthodologique - Modelli di giustizia costituzionale : saggion di critica metodologica, Bononia University Press - B.U.P., 2009, pp. 3436.

${ }^{59}$ Lord Irvine, Hansard, HL, 28 October 1998, col. 1983, cité dans F. ROUX, La dévolution en Grande-Bretagne, Contribution à la réflexion sur l'autonomie institutionnelle, op. cit., p. 193. En outre, un certain nombre d'amendements avaient, au cours des débats à propos des projets de lois de dévolution écossaise et galloise, proposé la création d'une cour constitutionnelle pour examiner les questions de répartition de compétence. Hansard, HL, col. 1963, 28 October 1998 ; Hansard, HC, col. 204, 12 May 1998 cités par F. ROUX, La dévolution en Grande-Bretagne, Contribution à la réflexion sur l'autonomie institutionnelle, op. cit., p. 193. 
constitutionnel, sont non seulement des Cours suprêmes mais aussi des cours ${ }^{60}$ ou du moins des juges constitutionnels ${ }^{61}$. Lorsqu'elles se prononcent sur des questions constitutionnelles, les Cours suprêmes comme les tribunaux ordinaires dans certains systèmes, et les Cours constitutionnelles sont toutes des juridictions constitutionnelles « chargées de la justice constitutionnelle » ${ }^{62}$, notion que nous appréhenderons dans un sens matériel. Suivant une définition suggérée, parmi d'autres, par le professeur Luc Heuschling nous entendrons la justice constitutionnelle comme désignant «toutes les procédures juridictionnelles portant sur la matière constitutionnelle » et, plus largement, "une justice portant sur la Constitution » ${ }^{63}$ quelle que soit sa nature. Il serait d'ailleurs possible de comprendre la première définition d'Eisenman selon laquelle « La justice constitutionnelle est cette sorte de justice ou mieux de juridiction qui porte sur les lois constitutionnelles $\gg{ }^{64}$ comme intégrant également des lois matériellement constitutionnelles qui font partie du cadre constitutionnel britannique ${ }^{65}$. Une telle approche permet

\footnotetext{
${ }^{60}$ En ce sens, cf. A. le DIVELLEC et M. de VILLIERS, Dictionnaire de droit constitutionnel, p. 101.

${ }^{61}$ L'utilisation du terme juge ou juridiction permet d'éviter toute confusion avec la conception de cour constitutionnelle développée par le professeur Louis Favoreu.

${ }^{62}$ L. FAVOREU, «Juridiction constitutionnelle », in O. DUHAMEL et Y. MENY (dir.),
} Dictionnaire constitutionnel, Paris, PUF, 1992, p. 547. Il convient de préciser que pour Charles Eisenmann la juridiction constitutionnelle est un système de «concentration de la justice constitutionnelle aux mains d'une juridiction unique » par opposition à la " justice constitutionnelle diffuse ». La juridiction constitutionnelle serait alors synonyme de Cour constitutionnelle. Charles Eisenmann, La justice constitutionnelle et la Haute Cour constitutionnelle d'Autriche, Paris, LGDJ, 1928, rééd., Paris, Economica, 1986, pp. 291-292.

${ }^{63}$ Souligné par l'auteur. Nous ne limiterons donc pas la notion de justice constitutionnelle au « contrôle de constitutionnalité des lois», ni à «l'ensemble des attributions des cours constitutionnelles », ni même à «tous les contentieux où un juge, quel qu'il soit, est amené à appliquer et à interpréter immédiatement les dispositions du texte de la Constitution ... au sens formel », autres définitions suggérées par L. HEUSCHLING, "Justice constitutionnelle et justice ordinaire. Epistémologie d'une distinction théorique», in C. GREWE, O. JOUANJAN, E. MAULIN, P. WACHSMANN (dir.), La notion de " justice constitutionnelle », coll. " Thèmes et commentaires », Dalloz, 2005, p. 89 et 111.

${ }^{64}$ C. EISENMANN, La justice constitutionnelle et la Haute Cour constitutionnelle d'Autriche, Paris, LGDJ, 1928, p. 1

${ }^{65}$ Dans la première partie de sa thèse esquissant une théorie de la justice constitutionnelle Charles Eisenmann étaye la définition de cette notion de la façon suivante : «En bref, le sens juridique de la justice constitutionnelle [...] est donc, en dernière analyse de garantir la répartition de la compétence entre législation ordinaire et législation constitutionnelle, d'assurer le respect de la compétence du système de règles ou de l'organe suprême de l'ordre étatique. » Il indique « D'où il suit immédiatement que, si - on croit l'avoir montré - elle est parfaitement concevable dans les États qui ne connaissent qu'une seule légalité, elle y présente toutefois un intérêt beaucoup plus réduit, étant nécessairement limitée au contrôle de l'observation des formes ». Il semble faire ici référence à l'existence possible d'une justice constitutionnelle dans les systèmes dotés de Constitution matérielle qui ne sont dotés que d'une seule légalité et qu'il définit comme «l'ensemble des règles sur la législation, c'est-à-dire sur la création des normes juridiques générales » en les distinguant des Constitutions «au sens formel » comme étant l'ensemble des lois dont la confection obéit à une procédure exceptionnelle par rapport à celle de la législation 
une analyse plus universelle et explicative qui n'exclue pas ab initio certains systèmes, comme ceux dotés de constitutions souples, du champ de la justice constitutionnelle.

L'analyse de la nature de la Cour suprême du Royaume-Uni interroge donc les notions de Cour suprême, de Cour constitutionnelle et, plus largement, de juridiction et de justice constitutionnelle compte tenu notamment des évolutions du constitutionnalisme britannique. C'est pourquoi l'approche adoptée dépassera la modélisation des systèmes de justice constitutionnelle à laquelle l'opposition entre Cour constitutionnelle et Cour suprême renvoie. L'analyse de la Cour suprême britannique confirme, nous le verrons, le caractère pédagogique, mais scientifiquement insatisfaisant ${ }^{66}$ de la classification fondée sur les modèles américain et européen de justice constitutionnelle ${ }^{67}$. Selon cette présentation, le modèle américain est un système de justice constitutionnelle au sein duquel le contrôle de constitutionnalité est diffus, concret, par voie d'exception, s'exerçant a posteriori et à l'origine de décisions ayant un effet inter partes. Le modèle européen se définit par des critères opposés en ce qu'il repose sur un contrôle de constitutionnalité concentré, abstrait, exercé par voie d'action et a priori conduisant à des décisions ayant un effet erga omnes ${ }^{68}$. Sans s'inscrire dans une telle classification, l'étude de la Cour suprême du Royaume-Uni ne se privera pas de l'utilisation d'un certain nombre de critères sur lesquels elle est basée. Ils permettront de situer cette juridiction par rapport à celles d'autres systèmes, sans pour autant en tirer de conclusion quant à l'appartenance de cette juridiction à un modèle.

L'objet de cette étude est, en effet, d'apprécier l'impact du CRA sur l'Appellate Committee de la Chambre des Lords devenu Cour suprême et de comparer ses caractéristiques institutionnelles et fonctionnelles avec celles des cours suprêmes et constitutionnelles afin d'en identifier la nature. Ces analyses seront l'occasion de déterminer, au regard des réformes introduites par le $C R A$, si la nature de cette juridiction a évolué « dans le temps » et de situer cette juridiction « dans l'espace » par rapport aux juridictions relevant d'autres systèmes constitutionnels. L'examen de l'expérience britannique

ordinaire. », cf. C. EISENMANN, La justice constitutionnelle et la Haute Cour constitutionnelle d'Autriche, op. cit., p. 3 et pp. 20-21.

${ }^{66}$ Sur ce point, cf. not., W. MASTOR réactualisant l'ouvrage de L. FAVOREU, Les Cours constitutionnelles, op . cit., p. 2 ; cf. également G. TUSSEAU, Contre les "modèles » de Justice constitutionnelle : essai de critique méthodologique - Modelli di giustizia costituzionale : saggion di critica metodologica, op. cit.

${ }^{67}$ Sur cette présentation, cf. not. L. FAVOREU, « Modèle américain et modèle européen de justice constitutionnelle », AIJC, 1988, p. 51.

${ }^{68}$ À ce propos, cf. L. FAVOREU, P. GAÏA, R. GHEVONTIAN, J.-L. MESTRE, O. PFERSMANN, A. ROUX, G. SCOFFONI, Droit constitutionnel, Dalloz, 2011, pp. 235-238 ; pp. 244-247. 
contribue ainsi à renouveler modestement le débat sur la notion de juge et de justice constitutionnelle.

L'apport du CRA est ambigu. Novateur par certains aspects, il est, par d'autres caractéristiques, seulement révélateur de ce qui existait déjà à l'époque de l'Appellate Committee de la Chambre des Lords. Cette loi n'est donc pas, à elle seule, à l'origine des transformations que connaissait la Haute juridiction britannique depuis longtemps. Elle présente un double apport qui ne fait que s'inscrire dans un mouvement plus général de mutation du constitutionnalisme britannique résultant de réformes et évolutions antérieures.

Le premier apport de la loi sur la réforme constitutionnelle de 2005 est purement formel. La rénovation de l'organisation et du fonctionnement de l'Appellate Committee de la Chambre des Lords «normalise» l'apparence de la Haute juridiction britannique. Elle se rapproche à cet égard d'autres juridictions, aussi bien suprêmes que constitutionnelles, qui présentent, du point de vue formel, des caractéristiques communes. Ces convergences sont toutefois insuffisantes pour éclairer la nature précise de la Cour suprême. Une telle identification dépend davantage d'aspects fonctionnels, dont la modification constitue le second apport du CRA. Cette loi a transféré les attributions de la Chambre des Lords et du Privy Council en matière de dévolution au profit d'une seule et même institution. Par cette concentration de compétences, le CRA réduit la singularité de la Cour suprême en confortant des convergences déjà existantes avec les fonctions d'autres Cours suprêmes.

\section{LA RÉNOVATION DE L'ORGANISATION ET \\ DU FONCTIONNEMENT DE L'APPELLATE COMMITTEE DE LA CHAMBRE DES LORDS : UNE « NORMALISATION » FORMELLE INSUFFISANTE}

En cherchant à rénover l'organisation et le fonctionnement de l'Appellate Committee de la Chambre des Lords le CRA révèle un double discours. Tout en voulant moderniser l'institution, il témoigne d'une volonté de ne pas bousculer l'ordre établi ${ }^{69}$. Le $C R A$ fait en quelque sorte « du neuf avec du vieux » en « dépoussiérant » l'Appellate Committee de la Chambre des Lords sans pour autant transformer radicalement les principes d'organisation et de fonctionnement. Les modifications formelles apportées à la Haute juridiction mettent, tout d'abord, en évidence l'ambiguïté de

${ }^{69}$ Lord Hope, «The Creation of the Supreme Court - Was it worth it ?», Barnard's Inn Reading, 24 June 2010 , p. 5. 
l'indépendance affichée de la Cour suprême. Elles modifient, par ailleurs, partiellement les garanties liées au statut des membres de la Cour suprême et transforment, enfin, de façon limitée les modalités de prise de décision.

\section{A. - Un affichage ambigu de l'indépendance de la Cour suprême}

S'expliquant par un objectif de transparence et de clarté institutionnelle ${ }^{70}$, la création de la Cour suprême a notamment été justifiée par une volonté d'afficher l'indépendance structurelle de la Cour suprême. Le CRA consacre ainsi des règles assurant son indépendance administrative et réglementaire par rapport à la formation parlementaire de la Chambre des Lords, faisant ainsi écho aux garanties d'indépendance dont bénéficient les juridictions suprêmes et constitutionnelles ${ }^{71}$. Cette convergence générale doit toutefois être relativisée en raison du caractère problématique de l'indépendance budgétaire de la Cour par rapport au Gouvernement.

\section{La consécration de l'indépendance administrative et réglementaire}

L'installation de la Cour suprême hors de l'enceinte du Parlement dans le bâtiment du Middlesex Guildhall sur Parliament Square, consacre au niveau géographique l'indépendance administrative de la Cour suprême. La clarification des rapports entre les formations juridictionnelles et parlementaires de la Chambre des Lords ne fait que consacrer au niveau institutionnel la réalité de la pratique existante. Il n'y a pas de changement fondamental quant à la participation des Law Lords aux travaux législatifs et des Lords non judiciaires aux travaux juridictionnels.

Les dernières interventions des membres non judiciaires de la Chambre des Lords dans la prise de décision juridictionnelle remontent, en pratique, à la moitié du $19^{\mathrm{e}}$ siècle $^{72}$. L'Appellate Jurisdiction Act 1876 impose une présence exclusive de juristes au sein de la formation juridictionnelle de la Chambre des Lords, outre la présence du Lord Chancelier. Ces membres sont désignés par la Reine à condition d'avoir détenu de «hautes fonctions

\footnotetext{
${ }^{70}$ En ce sens, Department for Constitutional Affairs Consultation Paper, Constitutional Reform: A Supreme Court for the United Kingdom, op. cit., § 1.

${ }^{71}$ À ce propos, cf. L. FAVOREU, P. GAÏA, R. GHEVONTIAN, J.-L. MESTRE, O. PFERSMANN, A. ROUX, G. SCOFFONI, Droit constitutionnel, op. cit., pp. 257-258.

${ }^{72}$ O'Connell v R. 8 (1844) 11 Cl. \& F. 155 HL; Rylands v. Fletcher (1868) L.R. 3 H.L. 330 HL; Bradlaugh v Clarke (1882-83) L.R. 8 App. Cas. 354. À ce propos, cf. T. BEVEN, « The Appellate Jurisdiction of the House of Lords II », LQR, 1901, p. 369 ; D. LEWIS JONES, « The Judicial Role of the House of Lords before $1870 »$, in L. BLOM-COOPER, B. DICKSON et G. DREWRY (dir.), The Judicial House of Lords 1876-2009, op. cit., p. 11 et D. PANNICK, " "Better that a horse should have a voice in the House [of Lords] than that a judge should" (Jeremy Bentham): replacing the Law Lords by a Supreme Court », op. cit., p. 715.
} 
judiciaires » ou d'être des membres de la formation parlementaire de la Chambre des Lords détenant ayant détenu de telles fonctions ${ }^{73}$. Ce n'est qu'en 2001, que le Lord Chancelier, Lord Irvine of Lairg, a siégé pour la dernière fois au sein de l'Appellate Committee en 2001 alors même qu'il était membre du Gouvernement ${ }^{74}$. Le $C R A$, qui met un terme à cette participation, formalise donc ce qui existait déjà dans les faits.

La participation des Law Lords aux travaux législatifs s'est également raréfiée en pratique. Jusqu'au début des années 1990, ils ont participé «librement et en grand nombre ${ }^{75}$ aux débats parlementaires ou ont siégé sans voter au sein de commissions ${ }^{76}$. Leurs interventions sont néanmoins devenues sporadiques. Après l'entrée en vigueur du Human rights Act le 2 octobre 2000, ils se sont engagés sous la présidence de Lord Bingham of Cornhill, à ne pas participer aux débats, à ne pas voter lorsqu'une question soulève une controverse politique importante et à ne pas exprimer publiquement une opinion sur une affaire susceptible d'être portée plus tard devant eux ${ }^{77}$. En supprimant le droit de siéger et de voter à la Chambre des Lords, la section 137 du $C R A$ entérine donc une convention constitutionnelle ${ }^{78}$ puisque le divorce était déjà existant dans les faits ${ }^{79}$. Il fallait cependant que le divorce soit non seulement réel mais aussi visible ${ }^{80}$, à défaut une simple

\footnotetext{
${ }^{73}$ Section 5 et 6 de l'Appellate Jurisdiction Act 1876.

${ }^{74}$ AIB Group (UK) Plc v. Martin [2001] UKHL 63.

${ }^{75}$ Lord Steyn, « Human Rights: The Legacy of Mrs Roosevelt », PL, 2002, 473.

${ }^{76}$ À propos de la participation des Law Lords aux travaux parlementaires, cf. D. HOPE, « Law Lords in Parliament», in L. BLOM-COOPER, B. DICKSON et G. DREWRY (dir.), The Judicial House of Lords 1876-2009, op. cit., pp. 164-177. Lord Hope of Craighead a, par exemple, participé à un débat sur la radiodiffusion en Écosse le 25 février 2009 : Hansard, HL, 25 February 2009, col. 277. Il a également présidé la Sous-Commission E du House of Lords European Union Select Committee. Lord Mance a introduit un rapport de la sous-commission E de l'Union européenne le 15 juillet 2009: Hansard, HL, 15 July 2009 col. GC265, éléments cités dans D. PANNICK, " "Better that a horse should have a voice in the House [of Lords] than that a judge should" (Jeremy Bentham): replacing the Law Lords by a Supreme Court », op. cit., p. 729. Cf. également le tableau retraçant la participation des Law Lords aux travaux parlementaires in O. GAY and R. KELLY, The Constitutional Reform Bill [HL] - the office of Lord Chancellor Bill No 18 of 2004-5, RP 05/05, 12 January 2005, p. 41.

77 Lord Bingham of Cornhill, Hansard, HL, 22 June 2000, col. 419, considère que les membres de la Chambre des Lords doivent suivent les mêmes lignes de conduite en matière d'impartialité que celles qui s'appliquent à tous les autres juges et qui ont été rappelés par la Cour d'appel dans l'affaire Locabail (UK) Ltd v. Bayfield Properties Ltd and others and four other actions [2000] 1 All E.R. 65 (CA). Cf. à ce sujet, B. DICKSON, «A Hard Act to Follow: The Bingham Court, 2000-8 », in L. BLOM-COOPER, B. DICKSON et G. DREWRY (dir.), The Judicial House of Lords 1876-2009, op. cit., p. 269.

${ }^{78}$ Lord Clarke of Stone cum Ebony, "The Supreme Court- one year on », Bracton Law Lecture, Exeter University, 11 November 2010, p. 6 disponible sur le site de la Cour suprême.

${ }^{79}$ Lord Mance, «Constitutional Reforms, the Supreme Court and the Law Lords », Civil Justice Quarterly, 2006, p. 160

${ }^{80}$ Lord Goodhart, Hansard, HL, 14 December 2004 co1. 210.
} 
modification du règlement de procédure, le standing order, aurait suffi ${ }^{81}$. La scission géographique des deux institutions a ainsi affiché cette indépendance aux yeux de tous.

Dotée d'un siège distinct du Parlement, la Cour suprême dispose également d'un personnel propre alors qu'elle était autrefois dépendante, au niveau administratif, du personnel de la Chambre des Lords. Celui-ci est désormais recruté au sein du Civil service et géré par le Président de la Cour, seul ou en collaboration avec le Lord Chancelier ${ }^{82}$. Le Secrétaire général, auquel le Président peut déléguer des fonctions non-judiciaires ou de désignation du personnel, est nommé par le Lord Chancelier après consultation du Président de la Cour suprême. Les agents administratifs sont, en revanche, désignés par le seul Président de la Cour. Leur nombre et les conditions de leur recrutement sont décidés par le Secrétaire général avec l'accord du Lord Chancelier. L'implication du Lord Chancelier semble en quelque sorte déplacer le pôle de dépendance administrative de la Haute juridiction du Parlement vers le Gouvernement. Néanmoins, le fait que le personnel de la Cour doive accomplir sa tâche en accord avec les directives du Président de la Cour et soit responsable uniquement devant lui garantit l'autonomie administrative de la juridiction.

La section 45(1) du CRA consacre également une autonomie dans l'établissement des règles de procédure qui relèvent de la compétence du Président de la Cour suprême après consultation du Lord Chancelier, des barreaux et Sociétés du droit anglais et gallois, écossais et nord-irlandais. Le Supreme Court rule 2009, adopté par le Parlement le $1^{\text {er }}$ juillet $2009^{83}$ et complété par des Directives établies par le Président de la Cour suprême, s'est substitué aux règles internes de la Chambre des Lords, les Civil, Criminal and Taxation Practice Directions and Standing Orders, qui organisaient jusque-là les procédures devant l'Appellate Committee de la Chambre des Lords. La validation ministérielle des règles de procédure envisagée, à l'origine, par le projet de loi, qui n'aurait fait que déplacer au profit du Gouvernement la dépendance réglementaire de la haute juridiction a heureusement été abandonnée ${ }^{84}$. L'apport du nouveau règlement est néanmoins limité sur le fond puisqu'il reprend, pour l'essentiel ${ }^{85}$, les règles procédurales qui s'appliquaient devant la Chambre des Lords à l'exclusion

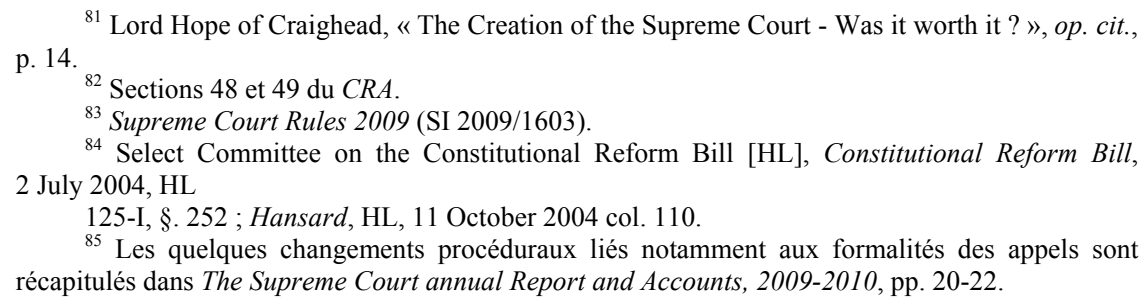

${ }^{85}$ Les quelques changements procéduraux liés notamment aux formalités des appels sont récapitulés dans The Supreme Court annual Report and Accounts, 2009-2010, pp. 20-22. 
de certaines conventions et pratiques qui s'appliquaient en raison de l'appartenance de l'Appellate Committee à la Chambre haute du Parlement. Sur la forme, les procédures ont perdu en solennité mais elles ont gagné en accessibilité et en transparence. La section 45(3) du CRA impose, en effet, que la Cour soit «accessible, juste et efficace» et que les règles de procédure soient «simples et exprimées simplement». Ces éléments révèlent une volonté d'assurer une proximité entre la Cour et les justiciables et de démocratiser cette nouvelle institution afin d'en asseoir la légitimité.

\section{Les limites de l'indépendance budgétaire}

Le financement de la Haute juridiction a fait l'objet d'une modification assez importante en passant d'un système de financement assuré par le Parlement à un système contrôlé par le Gouvernement. L'Appellate Committee était jusque là financé par le budget de l'Assemblée parlementaire de la Chambre des Lords qui pouvait garantir un montant de budget illimité à condition que les Lords parviennent à convaincre les Communes. L'indépendance financière de l'Appellate Committee, placé sous la responsabilité de la Chambre des Lords, est désormais confiée au Lord Chancelier par la Section 50(1)(b) du CRA. Ce dernier est tenu de s'assurer que la Cour suprême dispose de ressources qu'il estime " appropriées » pour accomplir ses fonctions. La mouture finale du texte de loi illustre un recul des garanties d'indépendance financière de la Cour suprême. Contrairement à ce que préconisait le Select Committe, la Cour suprême n'est pas libre de traiter directement avec le Trésor puisque son budget est sous la responsabilité du Ministère de la Justice ${ }^{86}$. Compte tenu de cette situation, le Président de la Cour suprême a estimé que ce dispositif ne garantissait pas de façon satisfaisante son indépendance puisqu'elle dépend de sa faculté de persuasion du Lord Chancelier ${ }^{87}$ qui lui a demandé, en des termes apparemment "péremptoires», de faire un certain nombre d'économies ${ }^{88}$. Le CRA révèle, sur cet aspect, un paradoxe. Sa section 3(1) impose au Lord Chancelier, aux autres ministres de la Couronne et à tous ceux qui ont des responsabilités en matière de justice ou d'administration de la justice de défendre l'indépendance durable du pouvoir judiciaire, mais est dans le même temps susceptible d'affecter les garanties financières jusque là accordées à la Haute juridiction pour des raisons de politique budgétaire. La dissociation entre l'Appellate Committee et la Chambre législative a rendu

${ }^{86}$ Select Committee on the Constitutional Reform Bill [HL], Constitutional Reform Bill, op. cit., §. 268.

${ }^{87}$ Lord Phillips of Worth Matravers, « Judicial independence and accountability: A view from the Supreme Court », op. cit., pp. 10-12.

${ }^{88}$ Ibid., p. 12. 
son indépendance plus visible, par rapport au Parlement, mais sans doute moins réelle par rapport au Gouvernement. Quoiqu'il en soit, le lien budgétaire entre certaines juridictions constitutionnelles et le Gouvernement existe dans d'autres systèmes. Il faut donc relativiser la portée de cette caractéristique, qui variera selon la nature des systèmes constitutionnels et des procédures budgétaires. Si aux États-Unis, le budget de la branche judiciaire dont la Cour suprême est la plus haute émanation dépend essentiellement du Congrès qui détient «le pouvoir financier, souvent appelé pouvoir de la bourse (power of the purse) ${ }^{89}$, la Cour constitutionnelle autrichienne dépend par exemple, dans son administration de la Chancellerie. Comme l'indique le professeur Wanda Mastor «le personnel est nommé par le chancelier et le budget est établi dans le cadre du budget annuel de la Fédération par le Conseil national ». À l'inverse la Cour constitutionnelle allemande «bénéficie d'une autonomie complète sur le plan administratif et financier ${ }^{90}$. L'effectivité de l'autonomie budgétaire de la Cour suprême du Royaume-Uni sera, en définitive, conditionnée par la pratique.

\section{B. - Une modification partielle du statut des membres}

Le CRA a partiellement modifié le statut des membres de l'Appellate Committee de la Chambre des Lords. Comparables sous plusieurs aspects à celles reconnues aux membres d'autres Cours suprêmes et constitutionnelles, les garanties d'indépendance entourant le mandat des membres de la juridiction sont maintenues. Le $C R A$ a, en revanche, modifié les modalités de désignation des membres sans en bouleverser les principes.

\section{Le maintien des garanties d'indépendance}

Il est, tout d'abord, intéressant de noter, du point de vue des seules apparences, que les douze membres de la Cour suprême du Royaume-Uni sont désormais appelés collectivement Justices ${ }^{91}$ à l'instar des membres de la Cour suprême américaine. Ils persistent cependant à s'appeler Lords dans leurs jugements, témoignant ainsi de l'ambivalence de l'apport du $C R A$. Ce point de convergence formel s'ajoute à un mandat dont les caractéristiques sont proches de celles des Justices américains. La section 33 du CRA reprend les règles régissant le mandat des Law Lords posées par la section 6

\footnotetext{
p. 267.

${ }^{89}$ E. ZOLLER, « Les pouvoirs budgétaires du Congrès des États-Unis », RFFP, n 86, 2004,

${ }^{90}$ W. MASTOR, Les Cours constitutionnelles, op. cit., p. 58.

${ }^{91}$ Section 23(6) du CRA.
} 
de l'Appellate Jurisdiction Act 1876 et la section 3 de l'Acte d'établissement de 1701 consacrant des principes similaires à ceux de l'article III, section 1 de la Constitution américaine ou de la section 125(2) de la Constitution indienne. À l'instar de leurs homologues américains et indiens les Justices de la Cour suprême du Royaume-Uni disposent d'un traitement - identique à celui des Lords of Appeal in Ordinary - dont le montant ne peut être réduit. Ils ont, par ailleurs, l'assurance de rester en fonction tant qu'ils auront une bonne conduite. Ils bénéficient ainsi d'une inamovibilité de fait et ne peuvent être démis de leur fonction que par une adresse des deux Chambres. Cette procédure, qui existe également pour les membres de la Cour suprême indienne et canadienne ${ }^{92}$, n'a, en pratique, jamais été mise en œuvre.

\section{La réforme des modalités de désignation}

Le processus de désignation des juges prévu par le $C R A$ formalise et complète les principes existants. Il vise à mettre un terme à la suspicion entourant la nomination des Law Lords et à rendre ce processus plus transparent afin d'asseoir la légitimité des membres de la Cour.

Jusqu'au CRA, les Lords of Appeal in Ordinary étaient désignés par la Reine sur recommandation du Premier ministre qui agissait sur les conseils $\mathrm{du}$ Lord Chancelier. Ce dernier réalisait la sélection des candidats en coopération avec les membres de la profession judiciaire. Ce processus de consultation, assez opaque malgré certaines évolutions ${ }^{93}$, pérennisait une corporation judiciaire basée sur le même moule. La désignation des juges de la Cour suprême est dorénavant précédée d'un processus de sélection conduit par une Commission composée de cinq membres ${ }^{94}$. Contrairement au silence de la Constitution américaine ou française, le $C R A$ exige, que les

${ }^{92}$ Art. 124 (4) de la Constitution indienne et art. 9 de la Loi sur la Cour suprême canadienne L.R.C. (1985).

${ }_{93}$ Ces évolutions ont eu lieu au début des années 1990 sous l'impulsion de Lord MacKay qui a voulu rendre le processus de sélection des juges plus transparent. La Law Society a proposé des recommandations en faveur de la mise en place d'une commission judiciaire de désignation indépendante. Law Society, Judicial Appointments: A Discussion Paper by the Remuneration and Practice Development and Courts and Legal Services Committees of the Law Society, March 1991. À ce propos, cf. C. FAIRBAIRN et S. BROADBRIDGE, Home Affairs Section, House of Common Library, "The Constitutional Reform Bill [HL] : a Supreme Court for the United Kingdom and judicial appointments », op. cit., pp. 48-49.

${ }_{94} \mathrm{La}$ procédure est prévue par les sections 25 à 31 et l'annexe $8 \mathrm{du} C R A$. La Commission est composée du Président de la Cour suprême, de son vice président, d'un représentant de la Commission de désignation judiciaire en Écosse, d'un représentant de la Commission de désignation judiciaire en Angleterre et au Pays de Galles et d'un représentant de la Commission de désignation judiciaire en Irlande du Nord. 
candidats aient certaines qualifications juridiques ${ }^{95}$, à l'instar des règles régissant la composition de certaines Cours constitutionnelles européennes ${ }^{96}$ ou des Cours suprêmes canadienne et indienne ${ }^{97}$. La Commission de sélection réalise un rapport à l'intention du Lord Chancelier, après diverses consultations ${ }^{98}$. Le Lord Chancelier est ensuite chargé de recommander ce candidat au Premier ministre en vue de sa désignation par la Reine et dispose d'un droit de veto limité. Une fois le candidat choisi par la Commission de sélection, le Lord Chancelier pourra accepter la proposition de la Commission, la rejeter ou demander à la Commission de considérer de nouveau son choix s'il ne l'estime pas approprié. À l'instar des membres de la Cour suprême indienne la procédure associe les juges à une désignation par l'organe exécutif ${ }^{99}$, mais en exclut le Parlement. En effet, si l'idée d'auditions de confirmation devant les commissions parlementaires ${ }^{100}$, telles qu'elles existent aux États-Unis a été émise, elle a rapidement été écartée. Le Gouvernement, les commissions parlementaires ${ }^{101}$, le Président de la

${ }^{95}$ La section 25 du CRA exige, comme l'article 6 de l'Appellate Jurisdiction Act 1876, que les candidats aient tenu de hautes fonctions judiciaires (Juge de la High Court d'Angleterre et du pays de Galles et d'Irlande du Nord, juge de la Cour d'appel d'Angleterre du pays de Galles et d'Irlande du Nord ou juge de la Court of Session en Écosse) pendant au moins deux ans ou aient exercé des fonctions d'avocat pendant quinze ans.

${ }^{96} \mathrm{Tel}$, par exemple, est le cas en Autriche, en Allemagne, en Espagne, en Italie, en Belgique ou au Portugal.

${ }^{97}$ Au Canada, le Gouverneur en Conseil désigne les membres de la Cour parmi les juges, actuels ou anciens, d'une cour supérieure provinciale et parmi les avocats inscrits pendant au moins dix ans au barreau d'une province selon les articles 4 et 5 de la loi sur la Cour suprême L.R.C. (1985). En Inde, la Constitution prévoit en son article 124 (3) qu'une personne, pour être désignée, doit être citoyen d'Inde, avoir exercé pendant au moins cinq ans en tant que juge ou avocat devant une Haute cour exerçant sa compétence sur l'ensemble du territoire indien ou dans plus de deux cours différentes ou est un « juriste distingué » d'après l'opinion du Président.

${ }^{98}$ La section $27 \mathrm{du}$ CRA envisage des consultations obligatoires des senior judges, du Lord Chancelier, du Premier ministre écossais, du Premier ministre Gallois et du Secrétaire d'État pour l'Irlande du Nord.

${ }_{99}$ Art. 124 de la Constitution indienne : «Les juges sont désignés par le Président après consultation des membres des Cours suprêmes et des Hautes cours des États et du Chief Justice ».

${ }^{100}$ À ce propos, cf. M. L. CLARK, «Introducing a Parliamentary Confirmation Process for New Supreme Court Justices: its Pros and Cons, and Lessons Learned from the US Experience ", PL, pp. 464-481.

${ }^{101}$ Department for Constitutional Affairs Consultation Paper, Constitutional Reform: A Supreme Court for the United Kingdom, CP11/03, July 2003, §. 45 ; House of Commons Constitutional Affairs Committee, Judicial appointments and a Supreme Court (court of final appeal), First Report, HC 48-1, 10 February 2004, $\$$ 85-87; Select Committee on the Constitutioal Reform Bill, Constitutional Reform Bill [HL], First Report, HL 125-I, 2 July 2004, §§. 412-419; House of Commons Constitutional Affairs Committee, Constitutional Reform Bill [Lords]: the Government's proposals, Third Report, HC 275-II, 28 January 2005, Oral and Written Evidence, Lord Falconer, QQ227. 
Cour suprême et le Master of the Rolls s'y sont opposés de crainte que la désignation des juges ne soit trop politisée ${ }^{102}$.

Composée, lors de son installation des anciens Law $\operatorname{Lords}^{103}$ et excluant la présence du Lord Chancelier ${ }^{104}$, la Cour doit, à l'instar de certaines Cours suprêmes et constitutionnelles, avoir une composition marquée par une certaine diversité, qui est cependant limitée dans les textes à une dimension géographique. La commission de sélection intervenant dans le processus de désignation doit veiller à ce que les candidats aient des connaissances et une expérience pratique du droit de l'ensemble des territoires britanniques ${ }^{105}$. Est ainsi consacrée une convention qui imposait la présence de juges écossais et nord-irlandais au sein de la juridiction suprême. Une représentativité géographique des juges existe donc, comme au Canada, en Belgique ${ }^{106}$ ou aux États-Unis jusqu'en $1891^{107}$. La représentativité sociale, notamment en terme de présence féminine, reste encore lacunaire, par rapport à celle du Canada ou des États-Unis ${ }^{108}$. À l'exception de la première et seule femme, la Baroness Hale of Richmond, à avoir été désignée à cette fonction les membres de la Cour suprême sont des hommes blancs, issus de classes sociales élevées, ce que semble regretter le Président de la Cour suprême lui-même ${ }^{109}$ et qui en fragilise la légitimité.

\section{C. - Une transformation limitée de la prise de décision}

La pratique qui a accompagné l'instauration de la Cour suprême révèle une transformation relative de la prise de décision. Sur la forme, on constate une nouvelle rédaction des arrêts inspirée de ceux de la Cour suprême

\footnotetext{
${ }^{102}$ Lord Clarke of Stone cum Ebony, « Selecting Judges: Merits, Moral, Courage, Judgement and Diversity », 22 september 2009, p. 5, disponible sur le site http://www.judiciary.gov.uk.

${ }^{103}$ Lord Clarke, Lord Dyson, Lord Wilson et Lord Sumption ont été désignés après l'entrée en fonction de la Cour suprême.

${ }^{104}$ Cf. Lord Chancellor (Transfer of Functions and Supplementary Provisions)(No. 2) Order 2006 (SI 1016/2006). La Cour suprême est aujourd'hui présidée par Lord Phillips of Worth Matravers et vice-présidée par Lord Hope of Craighead qui sont désignés dans les mêmes conditions que les autres membres.

${ }^{105}$ Section 27 (8) du CRA.

${ }^{106}$ En Belgique, l'article 31 de la loi spéciale du 6 janvier 1989 impose six juges d'expression française et six juges d'expression néerlandaise. Au Canada, l'article 6 de la loi sur la Cour suprême L.R.C. (1985) prévoit qu' « Au moins trois des juges sont choisis parmi les juges de la Cour d'appel ou de la Cour supérieure de la province de Québec ou parmi les avocats de celle-ci ».

${ }^{107}$ E. ZOLLER, « Présentation de la Cour suprême des États-Unis », CCC, n 5, 1998, p. 36.

${ }^{108}$ Parmi leurs neuf membres, quatre femmes sont juges à la Cour suprême canadienne et trois femmes à la Cour suprême américaine. On compte seulement deux femmes parmi les 30 membres (23 en effectif réel) de la Cour suprême indienne, ce qui est encore loin d'être représentatif.

${ }^{109}$ Lord Phillips, «Judicial Independence and Accountability: A view from the Supreme Court », op. cit., p. 3.
} 
américaine. Le $C R A$ a, par ailleurs, réduit, sans l'effacer, l'incertitude entourant les critères de composition des formations de jugement maintenant ainsi une pratique originale par rapport à celles d'autres juridictions.

\section{Une nouvelle rédaction des arrêts}

L'Appellate Committee de la Chambre des Lords rendait des jugements seriatim qui ne contenaient pas de motivation unique et collégiale $^{110}$. Marqués par la pratique parlementaire dont il était l'une des commissions, les arrêts de l'Appellate Committe étaient composés des différentes « opinions » de ses membres. Il ne s'agissait pas de jugements, car les Lords of Appeal étaient historiquement considérés comme membres d'une commission conseillant la Chambre au nom de laquelle le jugement était rendu. La motivation des jugements se trouvait donc dans les différentes opinions des Law Lords rendues les unes après les autres par ordre d'ancienneté ${ }^{111}$.

La forme des décisions de la Cour suprême ${ }^{112}$ est désormais similaire à celles de la Cour suprême américaine ${ }^{113}$. Les Lords ont rejeté l'idée d'un jugement unique, mais ont opté pour la technique américaine du « jugement de la Cour ». Les décisions peuvent désormais être rendues au nom de la Cour unanime par un ${ }^{114}$ ou plusieurs Justices ${ }^{115}$. La longueur des décisions est ainsi réduite ce qui en favorise l'accessibilité. Il est ainsi plus aisé de trouver le ratio decidendi d'un jugement rendu « au nom de la Cour » que de plusieurs opinions rendues les unes à la suite des autres. Lorsque la Cour n'est pas unanime, s'ajoutent à l'opinion majoritaire des opinions qualifiées $\mathrm{d}^{\prime}$ « individuelles » ${ }^{116}$ ou « concordantes » ${ }^{117}$, approuvant la décision majoritaire pour d'autres motifs et des opinions dissidentes, qui s'écartent

${ }^{110}$ À ce propos, cf. E. ZOLLER, «La pratique de l'opinion dissidente aux États-Unis », in Mélanges en l'honneur de Pierre Avril, Paris, Montchrestien, 2001, p. 610.

${ }^{111}$ L'Appellate Committee pouvait adopter une opinion de l'ensemble de ses membres, des opinions individuelles auxquelles certains juges ne faisaient qu'acquiescer ou une série d'opinions individuelles. Les opinions écrites conjointement par plusieurs Lords étaient relativement rares. À ce propos, cf. Lady HALE, «Judgement Writing in the Supreme Court», First Anniversary Seminar, 30 september 2010, p. 1. Disponible sur le site de la Cour suprême.

${ }_{112}$ À ce propos, cf. Lady Justice Arden, «A Matter of Style? The Form of Judgments in Common Law Jurisdictions : A comparison. Conference in Honour of Lord Bingham », Oxford, 28 June 2008, p. 10 disponible sur le site www.judiciary.gov.uk.

${ }^{113}$ À ce propos, cf. W. MASTOR, Les opinions séparées des juges constitutionnels, Paris/Aixen-Provence, Economica, PUAM, 2005.

${ }^{114}$ Application by Guardian News and Media Ltd [2010] UKSC 1.

${ }^{115} \mathrm{E}$ (Children) [2011] UKSC 27.

${ }^{116}$ E. ZOLLER, « La pratique de l'opinion dissidente aux États-Unis », op. cit., p. 609.

${ }^{117}$ Comme l'indique W. MASTOR dans sa thèse, Les opinions séparées des juges constitutionnels, op. cit., p. 18, certains qualifient à tort ces opinions d'opinions concurrentes « concurring opinions ». 
aussi bien des motifs que du dispositif de la décision. En pratique, parmi les cinquante sept premières décisions rendues au cours de la première année d'exercice de la Cour ${ }^{118}$, vingt étaient des jugements de la Cour ${ }^{119}$ et onze contenaient des opinions solidaires dans lesquelles les juges ne font qu' " apposer leur signature à une opinion rédigée par un ou plusieurs autres juges $»{ }^{120}$. L'importance de ce type de décision témoigne du développement de la collégialité au sein de cette nouvelle juridiction ${ }^{121}$. Ce nouveau formalisme dans la présentation des décisions n'a pas eu d'impact sur le fond des décisions ni sur la pratique des opinions dissidentes formulées par les juges puisqu'elles sont proportionnellement aussi nombreuses que devant la Chambre des Lords, mais semble-t-il moins nombreuses que celles que l'on trouve dans d'autres Cours suprêmes, telle qu'aux États-Unis, au Canada et en Australie ${ }^{122}$.

\section{L'incertitude entourant les critères de composition des formations} de jugement

Contrairement à ce qui prévaut devant les Cours suprêmes américaine et canadienne ou devant les Cours constitutionnelles autrichienne, italienne ainsi qu'espagnole et portugaise (pour certaines affaires seulement), la Cour suprême britannique ne siège ni en formation plénière ni en chambre, comme c'est le cas en Allemagne, en Belgique, en Espagne et au Portugal pour certaines affaires ${ }^{123}$. Les affaires sont, comme devant la Cour suprême indienne $^{124}$, entendues par des formations de jugement dont la composition est variable. Les sections 42 et 43 du CRA ont repris les conventions préexistantes devant la Chambre des Lords et permettent, en multipliant les formations, l'examen d'un plus grand nombre d'appels. Les formations peuvent être composées d'un nombre variable de juges : trois au minimum, cinq, sept ou neuf Justices lorsque l'affaire soulève des questions

\footnotetext{
${ }^{118}$ À ce propos, cf. Lady Hale, «Judgement Writing in the Supreme Court », op. cit., p. 2.

${ }^{119}$ Cf., par ex., Application by Guardian News and Media Ltd [2010] UKSC 1, [2010] 2 WLR 325 .

${ }^{120}$ W. MASTOR, Les opinions séparées des juges constitutionnels, op. cit., p. 18. Cf., par ex., In re Sigma Finance Corporation [2009] UKSC 2.

${ }_{121}$ Lady Hale a rappelé que cette nouvelle forme de décision devait permettre l'équilibre entre la responsabilité que doit endosser chaque juge pour ses propres décisions et l'adoption par la Cour suprême de jugements clairs susceptibles de donner une ligne de conduite aux juridictions inférieures. Elle a d'ailleurs appelé de ses vœux le développement d'un climat de «collégialité et de coopération dans les jugements rendus à la pluralité des voix », Lady Hale, "Judgement Writing in the Supreme Court ", op. cit., pp. 2-3.

${ }^{122}$ Lady Hale, «Judgement Writing in the Supreme Court », op. cit., p. 6.

${ }_{123}$ À propos du fonctionnement des cours européennes, cf. W. MASTOR, op. cit., p. 56 et s.

${ }^{124} \dot{A}$ ce propos, $c f$. «Entretien avec l'honorable K. G. Balakrishnan, président de la Cour suprême », $C C C$, n $^{\circ} 27,2009$, p. 61.
} 
importantes ${ }^{125}$. Ni le CRA, ni les Rules of the Supreme Court $2009^{126}$, ni les Practice Directions adoptées par le Président de la Cour suprême n'ont établi de critères précis de sélection des formations de jugement. Ces derniers, qui ne sont mentionnés qu'à titre indicatif sur le site internet de la Cour suprême, précisent que les cas dans lesquels une formation de plus de cinq juges devra siéger sont : un revirement de jurisprudence, des affaires soulevant les questions de haute importance constitutionnelle ou ayant une importance publique, les affaires concernant un conflit entre des décisions de la Chambre des Lords, de la Cour suprême et du Privy Council et les affaires soulevant une question importante relative à la Convention européenne des droits de l'homme. Le choix de la composition des formations de jugement reprend certains aspects de la pratique de l'Appellate Committee. Elles étaient choisies par les Clerks du Judicial Office de la Chambre des Lords et du Privy Council sous le contrôle de deux Senior Law Lords ${ }^{127}$, le Lord Chancelier pouvait également intervenir afin de sélectionner les formations. Désormais placée sous le contrôle du Président et du Vice-président, la composition persiste à tenir compte des domaines de compétences de chaque Law Lord et de leur origine géographique ${ }^{128}$.

Compte tenu du manque de clarté des critères conditionnant la constitution des formations de jugement, des auteurs et des juges ${ }^{129}$ ont plaidé en faveur de formations plénières, plus larges afin de garantir davantage de transparence et de "légitimité démocratique ${ }^{130}$ dans le traitement des décisions. D'autres observateurs ont proposé que les formations de jugement soient composées sur la base du hasard ou d'un roulement ${ }^{131}$. Bien que certains Lords ont admis qu'un changement de composition de la formation de jugement aurait pu modifier le contenu de la

${ }^{125}$ Cf. par ex., $R v$ Horncastle [2009] UKSC 14, [2010] 47 ; Application by Guardian News and Media Ltd [2010] UKSC 1 ; A v HM Treasury [2010] UKSC 2 où les Justices ont siégé à sept et $R(E) v$ Governing Body of JFS and others [2009] UKSC 15 ; Norris v Government of United States [2010] UKSC 9 et Chaytor and others v The Queen [2010] UKSC où les Justices ont siégé à neuf.

${ }^{126}$ S.I. $2009 / 1603$.

127 À ce propos, cf. D. OLIVER, "The Lord Chancelor as the Head of the Judiciary », in L. BLOM COOPER, B. DICKSON et D. DREWRY (dir.), The Judicial House of Lords 1876-2009, op. cit., p. 102 et A. Le SUEUR et R. CORNES, The Future of the United Kingdom's Highest Courts, 2001, cité dans R. CLAYTON, «Decision-making in the Supreme Court: new approaches and new opportunities », op. cit., p. 83.

${ }^{128} \mathrm{Ces}$ principes ont été diffusés en réponse à une enquête basée sur le Freedom of Information Act et repris par le professeur B. DICKSON, « The Processing of Appeals in the House of Lords ", LQR, 2007, p. 589.

${ }^{129}$ R. CLAYTON, "Decision-making in the Supreme Court: new approaches and new opportunities », PL, 2009, pp. 682-685 ; Lord Clarke of Stone cum Ebony, « The Supreme Courtone year on », op. cit., p. 17.

${ }^{130}$ R. CLAYTON, ibid., p. 685.

${ }^{131}$ R. BUXTON, « Sitting en banc in the new Supreme Court », LQR, 2009, pp. 292-293. 
décision ${ }^{132}$, le choix des panels persiste à être dominé par l'exercice d'un certain pouvoir discrétionnaire, ce qui peut affecter l'autorité et la légitimité des décisions.

En définitive, les rénovations formelles de la Cour suprême témoignent de l'ambivalence de l'apport du $C R A$. Vecteur de changement sous couvert d'une certaine continuité, cette loi a formalisé, en les précisant et en les clarifiant, des règles déjà latentes à l'époque de l'Appellate Committee de la Chambre des Lords. Cette officialisation change la perception de la Cour suprême, sans pour autant en asseoir incontestablement la légitimité. Marquée par la persistance de spécificités, la Cour suprême révèle un rapprochement, d'une intensité variable, avec les caractéristiques institutionnelles de certaines Cours, aussi bien suprêmes que constitutionnelles. Les nouvelles règles d'organisation et de fonctionnement ne sont donc pas décisives pour identifier la nature de la Cour suprême car elles existent sous des formes comparables devant ces deux types de juridiction. C'est donc vers les compétences de la Cour suprême qu'il convient de se tourner.

\section{LA CONCENTRATION DE COMPÉTENCES AU PROFIT DE LA COUR SUPRÊME : UNE SINGULARITÉ FONCTIONNELLE DÉCLINANTE}

Selon Lord Hope, la Cour suprême «n'a pas été configurée sur le modèle de la Cour suprême des États-Unis - [...] il s'est simplement agi d'un changement de nom, et non pas d'un changement de fonctions ou de compétences $\gg{ }^{133}$. À l'en croire, l'apport du CRA sur les fonctions de la Haute juridiction serait minime. Lord Phillips indique dans le même sens que « Les Law Lords qui deviendront les premiers juges de la Cour suprême seront dotés strictement de la même compétence que celle qui est la leur aujourd'hui ${ }^{134}$. Pourtant, le CRA ne s'est pas limité au transfert de compétences, déjà originales, de l'Appellate Committee de la Chambre des Lords vers la Cour suprême. Il a opéré un changement important en lui attribuant les compétences auparavant exercées par le Privy Council en matière de dévolution. Dans quelle mesure de telles fonctions correspondent-t-elles à celles exercées par une Cour suprême - qui est un juge suprême et constitutionnel - lorsqu'elle est entendue comme une

${ }^{132}$ R. CLAYTON, «Decision-making in the Supreme Court: new approaches and new opportunities », op. cit., p. 683. cit., p. 9.

${ }^{133}$ Lord Hope of Craighead, "The Creation of the Supreme Court - Was it worth it ? », op.

${ }^{134}$ Lord Phillips of Worth Matravers, «La Constitution du Royaume-Uni », CCC, hors série, Cinquantenaire du Conseil constitutionnel, 2009, p. 85. 
juridiction placée au sommet d'une hiérarchie de juridictions qui peut trancher en dernier ressort une diversité de contentieux, dont le contentieux constitutionnel et qui assure « la cohérence dans l'application du droit ${ }^{135}$ ? La concentration de compétences au profit de la Cour suprême perpétue les anciennes attributions de la Chambre des Lords et développe, à travers le contentieux de la dévolution, ses fonctions de juridiction suprême et constitutionnelle $^{136}$. Dès lors, le $C R A$ réduit, sans les effacer, les spécificités fonctionnelles de la Haute juridiction. Il fait de la Cour suprême tant une juridiction suprême atypique qu'une juridiction constitutionnelle singulière, qui reflète les transformations préexistantes du constitutionnalisme britannique. Le parachèvement de la nature de la Cour suprême et sa complète métamorphose dépendront de l'approfondissement de ces mutations constitutionnelles.

\section{A. - Une juridiction suprême atypique}

Le $C R A$ n'a pas véritablement «créé » de Cour suprême au RoyaumeUni puisqu'il a perpétué les compétences de l'Appellate Committee de la Chambre des Lords en les attribuant à une juridiction nouvellement dénommée ayant une même place dans l'ordre juridictionnel. Lord Wilberforce, Président de l'Appellate Committee, affirmait en 1978 qu' « Au Royaume-Uni de Grande-Bretagne et d'Irlande du Nord, un État dénué de constitution écrite, les fonctions de cour suprême sont remplies par la Chambre des Lords », tempérant immédiatement son propos en indiquant «Cette simple constatation, à laquelle des nuances seront apportées par la suite, révèle immédiatement le caractère unique de l'institution ${ }^{137}$. La Cour suprême est donc, à l'instar de la Chambre des Lords, une juridiction suprême atypique puisqu'elle maintient la compétence de dernier ressort à « géométrie variable » de sa devancière. L'attribution du contentieux de la dévolution tend cependant à réduire cette spécificité en développant indirectement les compétences de dernier ressort de la Cour suprême.

1. Le maintien d'une compétence de dernier ressort à "géométrie variable »

Avant 1'entrée en vigueur du $C R A$, certaines Cours étaient qualifiées de suprêmes sans en avoir les fonctions. Plusieurs textes de lois ont donné le

\footnotetext{
${ }^{135}$ S. GUINCHARD et T. DEBAR (dir.), Lexique des termes juridiques 2012, op. cit., p. 253.

${ }^{136}$ À cet égard, cf. not. C. GIRARD, "Le réalisme du juge constitutionnel britannique », $C C C, \mathrm{n}^{\circ} 22,2007$, p. 172.

${ }^{137}$ Lord Wilberforce, « La Chambre des Lords », RIDC, $\mathrm{n}^{\circ}$ 1, 1978, p. 85.
} 
titre de Cour suprême à la Haute Cour et à la Cour d'appel en Angleterre et au Pays de Galles ${ }^{138}$. En Irlande du Nord, existait la Supreme Court of Judicature $^{139}$, composée de la Cour d'appel, de la Haute Cour et de la Crown Court Nord-Irlandaises. En Écosse, la Court of Session et la High Court of Justiciary, juridictions statuant respectivement sur les appels civils et pénaux en Écosse, étaient également appelées Cours suprêmes ${ }^{140}$. Ces cours n'avaient, en réalité de suprême que le nom puisque parmi toutes ces juridictions, seule la High Court of Justiciary statuait (et statue toujours) en dernier ressort en Écosse ${ }^{141}$. Les décisions de toutes les autres juridictions étaient susceptibles de faire l'objet d'un appel devant l'Appellate Committee de la Chambre des Lords qui statuait en dernier ressort et était à cet égard une Cour suprême qui n'en avait pas la dénomination.

Qualifiée par la Section 40 du CRA de « superior court of record ${ }^{142}$, la Cour suprême est, à l'instar de la Chambre des Lords, une juridiction d'appel de dernier ressort ${ }^{143}$. Elle peut, comme d'autres Cours suprêmes ${ }^{144}$ et bien qu'elle ne le fasse plus toujours en pratique, examiner « en appel l'ensemble des points de droit et des points de fait que soulève une affaire ${ }^{145}$. Elle ne se limite donc pas à être un juge de cassation et dispose d'un «pouvoir de juridiction total ${ }^{146}$. Elle statue, à l'instar de la Cour suprême américaine ${ }^{147}$, sur la base de la common law, mais aussi de l'equity depuis la fin du XVII ${ }^{\mathrm{e}}$ siècle $^{148}$.

${ }^{138}$ The Supreme Court of Judicature Act 1873 ; The Supreme Court of Judicature (Consolidation) Act 1925; Supreme Court Act 1981. Elles sont aujourd'hui, en vertu de la section 59 (1) du Constitutional Reform Act 2005 dénommées Senior Courts.

${ }^{139}$ Elles sont, en vertu de la section 59 (1) du CRA 2005, dénommées : Courts of Judicature.

${ }^{140}$ Elles n'ont pas été renommées par la Section 59 (1) du CRA, mais sont dénommées Superior Courts par le Scottish Court Service lorsqu'elles sont présentées ensemble et Supreme Court, lorsqu'elles sont évoquées individuellement.

${ }^{141}$ Ses décisions sont définitives et ne sont pas susceptibles d'appel à l'exception des affaires de dévolution. Cf. section 124(2) du Criminal Procedure (Scotland) Act 1995.

${ }^{142}$ Il s'agit d'une Cour dont les procédures sont enregistrées et publiées et qui a le pouvoir de condamner pour le délit d'outrage à la Cour. À ce propos, cf. Hansard, HL, 13 december 2001, col. 1438

${ }^{143}$ On parle de «second tier appel tribunal», cf. à ce sujet, B. DICKSON, « The processing of Appeals in the House of Lords », LQR, 2007, p. 571. La Haute juridiction disposait aussi de compétences de premier et dernier ressort pour juger les pairs pour trahison ou autre crime très grave ou pour la procédure de destitution. La première compétence a été supprimée par le Criminal Justice Act 1948, la seconde a disparu en pratique. À ce propos, cf. Lord Wilberforce, « La Chambre des Lords », RIDC, $\mathrm{n}^{\circ} 1,1978, \mathrm{p} .88$.

${ }^{144}$ Par exemple la Cour suprême américaine, canadienne, japonaise et suédoise, pour n'en citer que quelques unes. Cf. à ce propos et pour d'autres exemples, A. TUNC, "Synthèse », RIDC, $\mathrm{n}^{\circ} 1,1978$, pp. 10-11.

${ }^{145}$ Ibid., p. 8 et p. 434.

${ }^{146}$ Ibid., p. 9.

${ }^{147}$ L'article III Section 2 [1] de la Constitution des États-Unis prévoit que « Le pouvoir judiciaire s'étendra à toutes les affaires, en droit et en équité, survenues sous l'empire de la présente Constitution, des lois des États-Unis, des traités conclus, ou qui seraient conclus, sous leur autorité ; 
Si cette compétence est étendue en pratique, elle n'est ni exclusive, ni exhaustive. Sa plénitude de compétence de dernier ressort pose certaines difficultés en l'absence d'un droit comparable à un droit fédéral ou à un droit de common law unifié ${ }^{149}$ résultant de l'existence de systèmes juridictionnels différents en Angleterre, en Écosse et en Irlande du Nord. La section 41(1) du CRA indique bien que les dispositions relatives aux compétences de la Cour n'affectent «pas la distinction entre les systèmes juridiques séparés des différentes parties du Royaume-Uni ».

Reprenant les compétences de la Chambre des Lords en vertu des Appellate Jurisdiction Acts de 1876 et de 1888, la Cour suprême est chargée d'examiner les appels en matière civile de la Cour d'appel et de la Haute Cour anglaise et galloise, nord-irlandaise et de la Court of Session écossaise ainsi que des appels en matière pénale des mêmes juridictions à l'exception de l'Écosse ${ }^{150}$. En effet, les appels en matière pénale continuent de relever, en dernier ressort, de la compétence de la High Court of Justiciary écossaise et ne sont susceptibles d'aucun recours ${ }^{151}$. Par ailleurs, ses décisions ont une autorité de chose jugée géographiquement circonscrite à l'ordre juridictionnel $\mathrm{du}$ territoire concerné ${ }^{152}$ et une autorité seulement persuasive pour les juridictions des autres territoires. La Cour est, en quelque sorte, une Cour, suprême régionalisée de chacun des territoires qui composent le RoyaumeUni, à l'exception partielle de l'Écosse. Cour suprême d'Angleterre, du Pays de Galles et d'Irlande du Nord aussi bien en matière civile que pénale, elle n'est qu'une Cour suprême civile pour l'Écosse. Elle n'est donc pas juridiquement une Cour suprême de l'ensemble du Royaume-Uni de Grande-Bretagne et d'Irlande du Nord. Sa mission « de veiller à la bonne

-- à toutes les affaires concernant les ambassadeurs, les autres ministres publics et les consuls ; dans lesquels les États-Unis seront partie ; -- aux différends entre deux ou plusieurs États ; -- entre un État et les citoyens d'un autre État; -- entre citoyens de différents États ; -- entre citoyens d'un même État réclamant des terres en vertu de concessions d'autres États, et entre un État, ou ses citoyens ou sujets étrangers $\gg$.

${ }^{148}$ Le fondement de cette compétence ne résulte d'aucun texte de loi, mais de décisions dans lesquelles la Chambre des Lords a accepté d'examiner des appels de la Cour of Chancery (Slingby v. Hale, 1669 et Shirley v. Fagg, 1675) cités dans J. S. HART, « The House of Lords and the Appellate Jurisdiction in equity 1640-1643 », Parliamentary History, vol. 2, 1983, pp. 49-70. Pour un exemple récent, cf. Jones v Kernott [2011] UKSC 53. cit., p. 375 .

${ }^{49}$ Le SUEUR, « New Labour's next (suprisingly quick) steps in constitutional reform », op.

${ }^{150}$ Section 40 (2) et (3) du CRA et l'annexe 9 du CRA.

${ }^{151}$ Pour certains auteurs, cette distinction constitue une atteinte au droit à un recours effectif reconnu par la CEDH et devrait être corrigée par l'extension des compétences de la Cour suprême aux appels des décisions pénales afin de permettre une interprétation uniforme des droits conventionnels. À ce sujet, cf. T. H. JONES, « Splendid Isolation: Scottish criminal law, the Privy Council and the Supreme Court », CLR, p. 100.

${ }^{152}$ Section 41 (2) du CRA. 
application des règles juridiques par les juridictions inférieures ${ }^{153}$ est ainsi morcelée entre chacun des ordres juridictionnels qui composent le Royaume-Uni, ce qui en fait une Cour suprême protéiforme.

Par ailleurs, en dépit du transfert du contentieux de la dévolution à la Cour suprême, la Commission judiciaire du Conseil privé de la Reine, Judicial Committee du Privy Council, reste compétent pour les appels des États membres du Commonwealth qui l'acceptent, des territoires d'outremer britanniques, des îles dépendantes de la Couronne et des zones dans lesquelles existe une bases militaires britanniques souveraines comme en Chypre. Certes, les membres de la Cour suprême sont également membres du Privy Council, mais la Cour est bien, en pratique, concurrencée par une autre juridiction suprême pour ces divers contentieux. Sa compétence de dernier ressort à géométrie variable et territorialement limitée fait donc obstacle à une qualification indiscutable de Cour suprême.

Outre le contentieux civil ou pénal, la Cour suprême s'est vue transférer d'autres compétences exercées par la Chambre des Lords parmi lesquelles on trouve notamment les contentieux militaires ou maritimes ${ }^{154}$. Elle peut entendre les appels des décisions de la Cour d'appel martiale ${ }^{155}$ et également connaître en dernier ressort des décisions des Cours maritimes qui font partie de la Queen's Bench Division de la Haute Cour puisque leurs décisions sont susceptibles d'appel devant la Cour d'appel, puis devant la Cour suprême. Là encore, certains litiges maritimes spécifiques échappent à la Cour suprême et relèvent de la compétence du Privy Council. Il s'agit des appels des décisions des Prize Courts qui sont des juridictions statuant sur des questions de saisie et de capture de navires en temps de guerre et des décisions de la Court of Admiralty de Cinque Port, qui est une province militaire et administrative particulière.

La Cour suprême ne dispose, par ailleurs, d'aucune compétence en matière ecclésiastique ni sur des décisions rendues par certains corps professionnels. Le Privy Council est, en effet, encore compétent pour examiner les appels des décisions de Cours ecclésiastiques ${ }^{156}$, de la Commission disciplinaire du Collège Royal des chirurgiens ainsi que les appels contre certaines réglementations des Church Commissionners chargés de gérer le patrimoine de l'Église d'Angleterre et contre les litiges relatifs aux incompatibilités parlementaires prévues par le House of Commons Disqualification Act 1975.

\footnotetext{
${ }^{153}$ A. TUNC, « La Cour suprême idéale », op. cit., p. 436.

${ }^{154} \mathrm{~L}$ 'ensemble de ces compétences sont listées dans l'annexe 9 du $C R A$.

${ }^{155}$ Section 274 de l'Armed Force Act 2006 et Section 39 du Courts-Martial (Appeals) Act 1968.

${ }^{156}$ Il entend les appels de l'Arches Court de Canterbury et de la Chancery Court de York.
} 
Ces éléments révèlent l'absence de compétence uniforme de la Cour pour statuer en dernier ressort. Comme la Chambre des Lords, la Cour suprême « est presque la seule cour d'appel suprême de la nation » ${ }^{157}$, mais elle n'est pas la seule puisqu'à ses côtés officie également le Privy Council. Cependant, la rareté et la spécificité du contentieux ecclésiastique et médical, nuance cette absence de monopole de la Cour suprême. On peut considérer, qu'elle est, en pratique, si ce n'est en théorie, majoritairement compétente en dernier ressort pour le territoire du Royaume-Uni de GrandeBretagne et d'Irlande du Nord. Par ailleurs, le fait que les membres du Conseil privé sont aussi membres de la Cour suprême montre que, dans les faits, ce sont les mêmes juges qui examinent les appels des affaires en provenance des États du Commonwealth qui l'acceptent ainsi que des territoires ou protectorat. C'est à condition de réunir ces attributions au sein d'une seule et même juridiction et de lui accorder une compétence pour le contentieux pénal écossais que la juridiction de dernier appel de la Cour suprême répondrait à celles d'une juridiction pleinement suprême pour le Royaume-Uni et le Commonwealth.

2. Le contentieux de la dévolution, facteur indirect de développement des compétences de dernier ressort

Le transfert des attributions du Privy Council à la Cour suprême en matière de dévolution a indirectement remis en cause son incompétence pour se prononcer en appel sur le contentieux pénal écossais ${ }^{158}$. La juridiction de la Cour suprême s'étend désormais de facto à ce contentieux par le biais de ses fonctions en matière de dévolution. Ces fonctions lui permettent de se prononcer, d'une part, sur la méconnaissance par un projet d'acte ou par un acte promulgué d'une entité dévolue des règles de répartition des compétences prévues par les lois de dévolution. Elle est, d'autre part, chargée de se prononcer sur la conformité de ces mêmes actes promulgués aux droits de l'Union européenne et de la Convention européenne des droits de l'Homme, qui constituent des «questions de dévolution $\gg{ }^{159}$.

Ainsi, des litiges relatifs à la répartition des compétences entre Westminster et les entités dévolues peuvent, tout d'abord, concerner des affaires pénales écossaises. Dans la décision Martin et Miller ${ }^{160}$ la Cour suprême a examiné si l'augmentation des pouvoirs de sanction pénale des

\footnotetext{
${ }^{157}$ A. TUNC, « Synthèse », op. cit., p. 12. Souligné par nous.

158 J. CHALMER, «Scottish appeals and the proposed Supreme Court», Edinburgh Law Review, 2004, p. 17.

${ }^{159}$ Cf. section 41 (4) du CRA. Les compétences de la Cour suprême en matière de dévolution sont développées infra, II.B.2.

${ }^{160}$ [2010] UKSC 10.
} 
Scheriffs résultant d'une modification de la section $45 \mathrm{du}$ Criminal Proceedings etc (Reform) (Scotland) Act 2007 relevait bien de la compétence du Parlement écossais. Elle a répondu par l'affirmative, jugeant que cette disposition qui impose une peine d'emprisonnement pour conduite sans permis n'outrepassait pas la compétence législative du Parlement écossais en matière pénale.

Ce sont, par ailleurs, surtout les litiges portant sur le respect des droits conventionnels par les autorités dévolues qui ont donné à la Cour suprême l'occasion d'investir le contentieux pénal écossais en tant que Cour de dernier ressort. La Cour suprême britannique dans l'affaire Cadder v. HM Advocate du 26 octobre $2010^{161}$ a jugé que l'utilisation par le Lord advocate d'aveux obtenus en garde à vue sans l'assistance d'un avocat méconnaissait l'article 6(3)(c) et 6(1) de la CEDH. Elle également jugé qu'une condamnation pour meurtre prononcée par la High Court of Justiciary en l'absence de divulgation par la Couronne de l'ensemble des informations et preuves à l'encontre du prévenu soulevait une contrariété avec l'article 6(1) $\mathrm{CEDH}^{162}$. La Cour suprême a considéré que cette condamnation devait être de nouveau examinée par la juridiction écossaise qui n'avait pas mis en œuvre le bon standard de contrôle. En pratique, le contentieux pénal écossais n'est donc plus hors de portée de la Cour suprême. Ses compétences constitutionnelles en matière de dévolution ont influencé sa compétence de dernier ressort puisqu'elle devient une juridiction de dernier ressort en matière pénale lorsque la dévolution est en cause. Dans ce domaine, la Cour rend des décisions ayant une autorité sur tout le territoire britannique. Elle est ainsi, à proprement parler, une juridiction suprême pour l'ensemble du Royaume-Uni dans le cadre limité du contentieux de la dévolution. Facteur indirect de développement des compétences de cette juridiction suprême atypique, le contentieux de la dévolution présente des répercussions plus directes sur les compétences de cette juridiction constitutionnelle singulière.

\section{B. - Une juridiction constitutionnelle singulière}

Compte tenu de ses attributions de juridiction suprême, la Cour au Royaume-Uni ne correspond tout d'abord pas à une Cour constitutionnelle définie, au sens strict, comme une juridiction exclusivement spécialisée dans le contentieux constitutionnel et située hors de l'appareil juridictionnel

${ }^{161}$ [2010] UKSC 43. Sur cette même question, cf. Jude (Respondent) v Her Majesty's Advocate (Appellant) (Scotland) Hodgson (Respondent) v Her Majesty's Advocate (Appellant) (Scotland) Birnie (Respondent) v Her Majesty's Advocate (Appellant) (Scotland) [2011] UKSC 55.

${ }^{162}$ Fraser v Her Majesty's Advocate [2011] UKSC24. 
ordinaire $^{163}$. Elle n'en dispose pas moins de compétences constitutionnelles originales autrefois exercées par la Chambre des Lords. Par ailleurs, en attribuant les compétences du Privy Council en matière de dévolution à la Cour suprême, la section 41(4)(b) $C R A$ lui confère une fonction de contrôle de la répartition des compétences territoriales s'accompagnant d'un contrôle de constitutionnalité des actes des entités dévolues, que l'on retrouve devant des juridictions constitutionnelles, quelles qu'elles soient ${ }^{164}$. En développant directement ses compétences constitutionnelles, cette nouvelle attribution rapproche la Cour suprême au Royaume-Uni d'autres juridictions constitutionnelles et réduit, par là même, ses spécificités.

\section{Le maintien de compétences constitutionnelles originales}

L'existence de compétences constitutionnelles de la Cour suprême est, pour ceux qui limitent à tort de telles compétences à la seule possibilité d'écarter une loi inconstitutionnelle, sujette à caution. Ainsi, A. Stevens indique que «La nouvelle appellation de cette juridiction est certes logique, puisqu'elle est la juridiction suprême (c'est-à-dire la plus élevée) dont les décisions sont insusceptibles d'appel, mais elle peut également être trompeuse car elle invite à la comparaison avec d'autres Cours suprêmes qui, elles, sont dotées de fonctions constitutionnelles. Or la nouvelle Cour suprême du Royaume-Uni n'est investie d'aucune fonction autre que celles déjà dévolues aux Lords of Appeal in Ordinary et ne pourra pas contrôler la validité ou la «constitutionnalité » d'une loi » ${ }^{165}$. Plusieurs Law lords se sont d'ailleurs basés sur cette idée pour souligner la principale différence entre la Cour suprême du Royaume-Uni et la Cour suprême américaine. Lord Mance insiste sur le fait que, la Cour suprême, ni aucune autre

${ }^{163} \mathrm{Cf}$. à propos de cette notion, L. FAVOREU, «Cours suprêmes et Cours constitutionnelles », op. cit., p. 277. Le professeur Laurence Burgorgue-Larsen a bien démontré que la Chambre des Lord était une Cour constitutionnelle, mais que ses pouvoirs ne rentrent pas dans la présentation faite par l'École d'Aix des Cours constitutionnelles relevant du modèle européen de justice constitutionnelle, «A European Perspective», L. BLOM COOPER, B. DICKSON et D. DREWRY (dir.), The Judicial House of Lords 1876-2009, op. cit., p. 398.

${ }^{164} \mathrm{De}$ telles compétences peuvent appartenir aussi bien aux Cours suprêmes que constitutionnelles. Une Cour suprême est compétente pour l'exercer dans les États fédéraux, comme aux États-Unis, au Canada ou en Inde. Cette compétence appartiendra à une Cour constitutionnelle en Allemagne, en Autriche ou en Belgique. Cf. pour des réflexions sur cette compétence dans les systèmes fédéraux, O. BEAUD, «De quelques particularités de la justice constitutionnelle dans un système fédéral », in C. GREWE, O. JOUANJAN, E. MAULIN, P. WACHSMANN, La notion de " justice constitutionnelle », op. cit., pp. 49-72. Ce contentieux se rencontre également dans les États régionaux, comme en Italie, en Espagne ou au Portugal, voire même dans un État unitaire décentralisé comme la France, à propos notamment du contentieux concernant les collectivités d'outre-mer autonomes ou la Nouvelle-Calédonie. Il sera exercé par une Cour constitutionnelle, cf. à ce sujet, W. MASTOR, L. FAVOREU, Les Cours constitutionnelles, op. cit., pp. 105-112.

165 A. STEVENS, «Le Conseil constitutionnel vu d'outre-manche : une énigme ? , CCC, $\mathrm{n}^{\circ} 25,2008$, Dossier $50^{\text {ème }}$ anniversaire, p. 59. 
juridiction britannique n'a le pouvoir de refuser l'application d'une loi considérée comme inconstitutionnelle ${ }^{166}$. Lord Bingham a évoqué, à propos de la comparaison dressée avec la Cour suprême américaine, le fait que « trop de personnes, en citant la Cour suprême, évoquent des images de la Cour suprême la plus connue dans le monde, c'est-à-dire celle des ÉtatsUnis, écartant l'application d'une loi du Congrès et affirmant la primauté de la Constitution. Il faut préciser que la Cour suprême du Royaume-Uni ne pourra jamais prétendre exercer un tel pouvoir $»^{167}$.

Bien qu'il en constitue un élément essentiel, le contentieux constitutionnel ne se limite pas au pouvoir d'annuler ou d'écarter une loi dans le cadre du contrôle de constitutionnalité. Il recouvre également le contrôle de la répartition des compétences entre les entités territoriales de l'État et entre organes politiques de l'État, le contrôle des élections ou des consultations populaires, la justice politique et la garantie des droits fondamentaux ${ }^{168}$. Dans cette perspective, il apparaît que la Cour suprême britannique dispose bien de fonctions constitutionnelles - certes originales qui s'étendent, comme devant certaines juridictions constitutionnelles, à certaines de ces compétences seulement ${ }^{169}$. Reflétant les spécificités du cadre constitutionnel souple du Royaume-Uni, fondé sur les conventions de la Constitution, les règles de «strict law» que sont la jurisprudence et les lois ayant une portée constitutionnelle ${ }^{170}$, ces attributions résident en un contrôle de constitutionnalité des lois spécifique principalement axé sur la

${ }^{166}$ Lord Mance, «Constitutional Reforms, the Supreme Court and the Law Lords », op. cit., pp. $155-165$

${ }^{167}$ Lord Bingham, «A New Supreme Court for the United Kingdom », The Constitution Unit, Spring Lecture 2002, 1rst May 2002, p. 10. Même sens, cf. Lord Hope of Craigehead, «Do we really need a Supreme Court? ", Newcastle Law School, 25 November 2010, p. 16 disponible sur le site de la Cour suprême, p. 9.

${ }^{168}$ Dans son «Aperçu d'une histoire des fonctions de la justice constitutionnelle en Allemagne (1815-1933) », in C. GREWE, O. JOUANJAN, E. MAULIN, P. WACHSMANN (dir.), La notion de "justice constitutionnelle», op. cit., p. 15, O. Jouanjan modélise les «fonctions essentielles » de l'actuelle Cour constitutionnelle en distinguant ces six fonctions. Cf. à cet égard, not., L. FAVOREU, P. GAÏA, R. GHEVONTIAN, J.-L. MESTRE, O. PFERSMANN, A. ROUX, G. SCOFFONI, Droit constitutionnel, op. cit., pp. 260-267 et G. DRAGO, Contentieux constitutionnel français, Paris, PUF, 2011, pp. 57-92 qui distinguent également ces fonctions en les classant autour d'une fonction d'unification de l'ordre juridique, une fonction de protection des droits fondamentaux, une fonction d'arbitrage entre les pouvoirs publics et une fonction de contrôle de l'expression du suffrage.

${ }^{169}$ Pour se limiter à quelques exemples, les Cours constitutionnelles espagnole et belge ne sont, par exemple, pas compétentes en matière électorale. W. MASTOR, Les Cours constitutionnelles, op. cit., p. 112. Par ailleurs, la Cour suprême canadienne n'était, jusqu'à l'adoption de la Charte des droits fondamentaux de 1982, pas explicitement compétente en matière de droits fondamentaux.

${ }^{170}$ À ce propos, cf. A.V. DICEY, «Introduction à l'étude du droit constitutionnel », op. cit., pp. 21-23. 
garantie des droits fondamentaux et en des compétences extérieures à un tel contrôle.

La Cour suprême dispose, en premier lieu, de compétences originales dans le domaine du contrôle des normes et de la garantie des droits fondamentaux, souvent présentés comme les fonctions essentielles des juridictions constitutionnelles. Si le contrôle des actes infra-législatifs ne pose pas de difficulté particulière, celle du contrôle des lois se heurte au principe de souveraineté du Parlement qui empêche, en principe, toute juridiction d'écarter, d'abroger ou d'annuler une loi. Ce principe connaît cependant une érosion progressive résultant de l'insertion du Royaume-Uni dans le cadre européen. Les juges britanniques peuvent, en effet, depuis l'arrêt Factortame ${ }^{171}$ et en vertu du European Communities Act 1972, écarter des lois contraires au droit de l'Union européenne. Avec l'adoption du Human Rights Act 1998, ils sont également compétents pour contrôler des lois par rapport à la Convention européenne de sauvegarde des droits de l'Homme et des libertés fondamentales $(\mathrm{CEDH})$ et les déclarer incompatibles avec les droits qu'elle reconnaît. Est ainsi apparu au Royaume-Uni un contrôle de constitutionnalité des lois original, limité et européanisé.

Ce contrôle de constitutionnalité est, tout d'abord, original en ce que le HRA 1998 et le EC Act 1972 sont matériellement des éléments de la Constitution souple du Royaume-Uni, mais elles se distinguent également, formellement des lois ordinaires si l'on suit la décision de la High Court, Thoburn v. Sunderland City Court ${ }^{172}$. Le juge Laws a reconnu, dans cette affaire, l'existence de lois «constitutionnelles », au nombre desquelles on

${ }^{171} R v$. Secretary of State for Transport, ex parte Factortame Ltd (No. 2) [1991] 1 AC 603, [1991] 1 All ER 70. À propos de l'affaire Factortame, cf. not. T. R. S. ALLAN, «Parliamentary Sovereignty : Law, Politics, and Revolution ", $L Q R, 1997$, p. 449 ; S. BOYRON et L. N. BROWN, «L'affaire Factortame : droit communautaire contre droit public anglais », RFDA, 1994, vol. 10, $\mathrm{n}^{\circ}$ 1, pp. 70-79; P. CRAIG, " Sovereignty of the United Kingdom after Factortame », YEL, 1991, vol. 11, pp. 221-255 ; P. CRAIG, «Britain in the European Union », in J. JOWELL et D. OLIVER, The Changing Constitution, Oxford/New York, Oxford University Press, 2004, p. 103 ; E. GARCIA de ENTERRIA, « Un pas décisif dans le droit constitutionnel britannique : le pouvoir des juges de juger de façon abstraite et générale les lois du Parlement en contradiction avec le droit communautaire "), in Liber amicorum Marc-André Eissen, Bruxelles, Paris, Bruylant, LGDJ, 1995, pp. 165-186; I. LOVELAND, «Britain and Europe », in V. BOGDANOR, The British Constitution in the Twentieth Century, Oxford, Oxford University Press, 2003 ; H.W.R. WADE, « SovereigntyRevolution or Evolution?», $L Q R$, 1996, vol. 112, pp. 568-575; "What Has Happened to the Sovereignty of Parliament? », LQR, 1991, vol. 107, pp. 1-4.

${ }^{172}$ [2002] EWHC 195, [2002] 3 WLR 247. À ce propos, cf. D. CAMPBELL et J. YOUNG, "The Metric Martyrs and the Entrenchment Jurisprudence of Lord Justice Laws », PL, 2002, pp. 399-406; M. ELLIOTT, «Embracing «Constitutional» Legislation: Toward Fundamental Law? ", NILQ, 2003, vol. 54, n 1, pp. 25-42 ; G. MARSHALL, " Metric Measures and Martyrdom by Henry VIII Clause », $L Q R, 2002$, vol. 118, pp. 493-502. K. A. ARMSTRONG, «United Kingdom-Divided on Sovereignty? », in N. WALKER (dir.) Sovereignty in Transition, Oxford, Portland/Oregon (Or.), Hart Publishing, 2003, p. 339. 
trouve le EC Act 1972 et le HRA 1998 aux côtés de lois historiques telles que la Magna Carta 1215, le Bill of Rights 1688, le Petition of Rights 1628, 1'Act of Settlement 1701 et les Parliaments Act 1911. Le régime de ces lois « constitutionnelles » diffère de celui des lois ordinaires puisqu'elles font exception à la doctrine de l'abrogation implicite. Elles ne peuvent être abrogées que de façon expresse par le législateur. La modification de telles lois est donc réalisée selon une procédure «exceptionnelle » ${ }^{173}$ qui peut laisser percevoir une distinction formelle entre lois ordinaires et constitutionnelles au Royaume-Uni. Il apparaît ainsi une formalisation, une « rigidification » des lois composant la Constitution britannique.

Ce contrôle est, ensuite, limité dans son champ d'application au droit européen. Depuis la décision Factortame, dans laquelle la Chambre des Lords a reconnu la possibilité de suspendre une loi, les juridictions britanniques n'hésitent plus à ne pas appliquer des lois contraires au droit de l'Union européenne $^{174}$. Elle effectue, dans ce domaine, un véritable contrôle de la loi dont les effets sont comparables au contrôle effectué dans le système américain puisque la loi est privée d'effet en l'espèce et non pas abrogée ou annulée comme devant certaines Cours constitutionnelles. Pour l'heure, la Cour suprême n'a pas eu l'occasion d'effectuer un tel contrôle, mais a notamment été amenée à contrôler la validité d'un mandat d'arrêt européen ${ }^{175}$, à interpréter une directive européenne sur l'habitat ${ }^{176}$ et à juger non-discriminatoires les conditions d'attribution préférentielles au bénéfice des citoyens irlandais d'une allocation, le State pension Credit ${ }^{177}$.

Le contrôle juridictionnel des lois est également limité au champ d'application du droit de la Convention européenne des droits de l'homme avec le $H R A$. Dans ce cadre particulier, le contrôle exercé est d'une portée limitée. Le $H R A$ 1998, entré en vigueur le 2 octobre 2000, a incorporé la plupart $^{178}$ des dispositions de la Convention européenne des droits de l'homme dans l'ordre juridique britannique et introduit une forme originale de contrôle de la loi. Depuis maintenant plus de dix ans, certaines Cours britanniques, dont la Cour suprême, ne parvenant pas à interpréter une

\footnotetext{
${ }^{173}$ Charles Eisenmann indique que la Constitution au sens formel est « l'ensemble des lois dont la confection obéit à une procédure exceptionnelle par rapport à celle de la législation ordinaire », in La justice constitutionnelle et la Haute Cour constitutionnelle d'Autriche, op. cit., p. 3 .

${ }^{174}$ Cf., par ex., Marshall v. Southampton and South-West Hampshire Area Authority (No 2) [1994] ICR 242 ; Equal Opportunity Commission v. Secretary of State for Employment [1995] 1 AC 1, [1994] 2 WLR 409 ; Bossa c. Nordstress Ltd [1998] IRLR 284.

${ }^{175}$ Louca v A German Judicial Authority (Criminal Appeal from High Court of Justice) [2009] UKSC 4

${ }^{176}$ Morge v Hampshire County Council [2011] UKSC 2.

${ }^{177}$ Patmalniece v SSWP [2011] UKSC10.

${ }^{178} \mathrm{La}$ section $1 \mathrm{du} H R A$ a incorporé les droits et libertés fondamentaux consacrés dans les articles 2 à 12 et $14 \mathrm{CEDH}$, les articles $1^{\text {er }}$ à 3 du premier Protocole et $1^{\text {er }}$ et 2 du $6^{\text {ème }}$ Protocole.
} 
législation primaire ou subordonnée ${ }^{179}$ conformément aux droits conventionnels, sont compétentes pour prononcer une déclaration d'incompatibilité. Si toutes les juridictions peuvent effectuer une interprétation des lois conforme à la $\mathrm{CEDH}^{180}$, seules les plus Hautes juridictions ${ }^{181}$ sont compétentes pour prononcer une déclaration d'incompatibilité qui n'affecte pas « la validité, le maintien en vigueur ou la mise en œuvre de la disposition législative ${ }^{182}$. Une telle déclaration ne donne en aucun cas la possibilité au juge d'écarter les lois en contrariété avec le $H R A$ en raison du principe de souveraineté parlementaire. Elle constitue une invitation à l'attention des autorités politiques de modifier la disposition législative dont la contrariété a été dénoncée. Il s'agit d'une décision juridictionnelle qui n'a pas d'effet juridique sur la loi dont la contrariété a été constatée, mais qui est susceptible d'avoir des effets politiques si le Gouvernement propose de corriger l'incompatibilité par la voie législative ordinaire ou par une procédure de remedial order ${ }^{183}$. Tout en cherchant à sauvegarder le principe de souveraineté parlementaire, cette procédure autorise les cours à contrôler les lois. Apparaît ainsi un contrôle juridictionnel des lois original, que plusieurs auteurs et certains juges ont comparé au contrôle de constitutionnalité ${ }^{184}$. Les plus hautes juridictions britanniques, au premier rang desquelles se trouve la Cour suprême, s'engagent ainsi dans un raisonnement comparable à celui des Cours

${ }^{179}$ Il s'agit de l'hypothèse dans laquelle la législation subordonnée est prise sur le fondement d'une législation primaire ce qui empêche la disparition de l'incompatibilité : Section 4 (3),(4) du HRA.

${ }^{180}$ La section 3 du HRA prévoit que « dans la mesure du possible, les législations primaires et subordonnées doivent être lues et mises en œuvre de façon compatible avec les droits conventionnels ».

${ }^{181}$ Cette déclaration ne peut être effectuée que par la Cour suprême, le Comité judiciaire du Conseil Privé, la Cour Martiale d'Appel, la Haute Cour de justice ou la Cour de session en Écosse ; la Haute Cour ou la Cour d'appel en Angleterre et au Pays de Galles, en Écosse ou en Irlande du Nord (section 4 (5) du HRA 1998).

${ }^{182}$ Section 4 (6)(a) du HRA.

${ }^{183}$ Cette modification peut avoir lieu par l'intermédiaire d'un projet, d'une proposition de loi ou de la procédure de remedial order comparable à celle des ordonnances en France, prévue par la section 10 du HRA.

${ }^{184}$ Not. D. FELDMAN, "Standards of Review and Human Rights in English Law », in D. FELDMAN et P. BIRKS (dir.), English Public Law, Oxford/New York, Oxford University Press, 2004, p. 422 ; Lord Hoffmann, « Human Rights and the House of Lords », MLR, 1999, vol. 62, $\mathrm{n}^{\circ} 2$, p. 160 ; Lord Irvine of Lairg, "Sovereignty in comparative perspective : Constitutionalism in Britain and America », New York University Law Review, 2001, vol. 76, $\mathrm{n}^{\circ}$ 1, pp. 1-22; J. JOWELL, "Beyond the Rule of Law: Toward Constitutional Judicial Review », PL, 2000, pp. 671-683 ; A. KAVANAGH, Constitutional Review under the UK Human Rights Act, Cambridge University Press, 2009. Cette idée est également abordée dans la communication d'A. ANTOINE, «Les enjeux de la création d'une Cour suprême au Royaume-Uni et la Convention européenne des droits de l'homme et des libertés fondamentales », op. cit., p. 289 et O. DEPARIS, «La Cour suprême au Royaume-Uni et la question de constitutionnalité », $C C C, \mathrm{n}^{\circ}$ 32, 2011, pp. 223-231. 
suprêmes ou des Cours constitutionnelles ${ }^{185}$. La principale différence est l'issue de ce contrôle puisque, dans le cas britannique, la loi reste en vigueur. Malgré cela, le mécanisme de contrôle des lois instauré par la procédure de déclaration d'incompatibilité peut être envisagé comme une forme européanisée et inaboutie de contrôle des lois. Elle constitue une variante du contrôle de constitutionnalité des lois par rapport aux droits et libertés constitutionnellement garantis que l'on rencontre dans la majorité des systèmes constitutionnels. Le Président de la Cour suprême a ainsi affirmé que «Le $H R A$, qui exige des Cours non seulement d'examiner les agissements de l'exécutif, mais aussi les lois afin de s'assurer qu'ils respectent les droits de l'homme, a donné à la Cour suprême certaines des fonctions d'une Cour constitutionnelle ${ }^{186}$. La Cour suprême est donc bien un juge constitutionnel qui connaît un contentieux des droits de l'homme croissant. Ses premières décisions, qui s'inscrivent dans la continuité de celles de la Chambre des Lords ${ }^{187}$, n'ont rien à envier aux décisions rendues par d'autres juridictions constitutionnelles en ce domaine. La Cour suprême a, par exemple, déclaré la section 82 (1) du Sexual Offences Act 2003, qui impose aux personnes condamnées à une peine de prison d'au moins trente mois une obligation de notification permanente de leur résidence et de leurs déplacements à l'étranger aux autorités de police, incompatible avec l'article $8 \mathrm{CEDH}^{188}$. Elle a également déclaré illégale la détention indéfinie des empreintes $\mathrm{ADN}$ de personnes acquittées, en préférant procéder à une interprétation conforme de la section 64(1A) du Police and Criminal Evidence Act $1984^{189}$. De même, l'article 8 de la CEDH a permis d'interpréter le Children (Scotland) Act 1995 afin qu'un père non-marié et séparé de sa compagne puisse assister à l'audience établissant la future situation de son enfant ${ }^{190}$. Le contentieux des droits de l'homme ne se limite pas au contrôle des lois, puisque la Cour suprême s'est également assurée, dans une décision qui rappelle la décision 14/22 QPC sur la garde à vue du Conseil constitutionnel français ${ }^{191}$, de la garantie effective du droit à un avocat pendant la garde à vue en Écosse, dans la décision Cadder v. HM

\footnotetext{
${ }^{185}$ En ce sens, cf. S. GARDBAUM, « The New Commonwealth Model of Constitutionalism », Am.J.Comp.L., 2001, vol. 49, p. 738.

${ }^{186}$ Lord Phillips of Worth Matravers, « The Challenges of the Supreme Court», op. cit., p. 34.

${ }^{187} \mathrm{Cf}$., pour citer la plus marquante de ces dernières années, la décision $A$ and others $v$. Secretary of State for the Home Department, [2004] UKHL 56 ayant déclaré incompatible la section 23 de l'Antiterrorism Crime and Security Act 2001 (ATCSA).

${ }^{188} R$ (on the application of $F$ (by his litigation friend $F$ )) and Thompson (FC) (Respondents) $v$. Secretary of State for the Home Department (Appellant) [2010] UKSC 17.

${ }^{189} R(G C) v$ The Commissioner of Police of the Metropolis; $R(C) v$ The Commissioner of Police of the Metropolis [2011] UKSC21.

${ }_{190}$ Principal Reporter $v$ K \& Ors [2010] UKSC 56.

${ }^{191}$ Cons. const. ${ }^{\circ} 2010-14 / 22$ QPC, 30 juill. 2010, M. Daniel W. et autres [Garde à vue], JO du 31 juillet 2010, p. 14198.
} 
Advocate du 26 octobre $2010^{192}$. L'importance du contentieux des droits de l'homme devant la Cour suprême, montre que le Royaume-Uni s'inscrit dans un mouvement global que connaissent toutes les juridictions constitutionnelles.

Le contrôle de constitutionnalité des lois est, enfin, européanisé, car lorsqu'elle exerce un contrôle sur la base du EC Act 1972 ou du HRA 1998, la Cour suprême assure aussi bien la primauté de lois " constitutionnelles ", dans le sens de l'arrêt Thoburn, que celle des traités européens. Elle est ainsi compétente pour réaliser un contrôle mixte qui emprunte à la fois au contrôle de constitutionnalité et de conventionnalité. L'exercice de ce contrôle combiné, dominé par les droits fondamentaux et européanisé, donne naissance à un contentieux dont la nature se rapproche de celui des juridictions constitutionnelles européennes ${ }^{193}$.

La Cour suprême dispose, en second lieu, de compétences constitutionnelles extérieures au contrôle des lois. Certes, des questions susceptibles d'être rattachées au contentieux constitutionnel échappent à la Cour suprême. On constate ainsi une absence de juridictionnalisation des conflits entre organes politiques de l'État et une incompétence de la Cour suprême pour examiner le contentieux électoral, national ou local qui relève de juridictions crées ad hoc ou de juridictions de droit commun. Ce contentieux ne remonte pas jusqu'à la Cour suprême, les décisions de la Cour d'appel étant définitives en vertu de la section 157 du Representation of the People Act 1983. Le contentieux électoral de la Chambre des communes s'articule, d'ailleurs, avec les pratiques et les règles des commissions parlementaires compétentes de cette Chambre ${ }^{194}$. Le House of Lors Disqualification Act 1975, qui réglemente également la déchéance des fonctions de membres de la Chambre des Communes en cas de faillite, de condamnation pénale ou d'incapacité au terme de la loi sur la santé mentale permettra, par exemple, au Président de la Chambre des Communes de déclarer un siège vacant ${ }^{195}$.

Il n'existe, par ailleurs, pas de justice politique relevant de la compétence d'une Cour spécialisée existant en Allemagne, en Italie ou en Autriche ${ }^{196}$ et la procédure de destitution, telle qu'on la rencontre aux États-

192 [2010] UKSC 43.

193 À ce propos, cf. L. BURGORGUE-LARSEN, " A European Perspective », in L. BLOM COOPER, B. DICKSON ET D. DREWRY (dir.), The Judicial House of Lords 1876-2009, op. cit., pp. 401-412.

${ }^{194}$ Section 157 (2) du Representation of the People Act 1983.

195 À ce propos, cf. A. STEVENS, «Le Conseil constitutionnel vu d'outre-manche: une énigme ?», $C C C, \mathrm{n}^{\circ} 25,2005$, Dossier $50^{\text {ème }}$ anniversaire, p. 60.

${ }^{196}$ En Allemagne, en Autriche ou en Italie par exemple. À ce propos, cf. W. MASTOR, Les Cours constitutionnelles, op. cit., pp. 119-120. 
Unis est devenue obsolète à la faveur d'un contrôle politique ${ }^{197}$. Cependant, la Cour suprême peut être amenée, à l'instar de toute juridiction, à juger le personnel politique au civil ou au pénal. En effet, la Rule of Law implique un principe d'égalité devant la loi qui suppose que « tout homme, quels que soient son rang, sa condition, est soumis à la loi ordinaire du royaume et justiciable des tribunaux ordinaires. [...] tous les fonctionnaires, depuis le premier ministre jusqu'aux constables ou aux collecteurs de taxes, sont soumis à la même responsabilité que n'importe quel autre citoyen pour tout acte fait sans justification légale ${ }^{198}$. Il n'existe donc pas de juge d'exception en ce domaine. La Cour suprême a d'ailleurs été amenée à rendre une décision dans l'affaire des notes de frais qui a secoué la classe politique en 2009. Elle a jugé que l'immunité parlementaire ne s'appliquait pas à trois membres de la Chambre des communes et un membre de la Chambre des Lords accusés de fausses déclarations relatives à leurs dépenses. Selon la Cour suprême, l'article 9 du Bill of Rights qui renvoie aux débats au sein du Parlement ne s'applique pas à de telles déclarations ${ }^{199}$. Ces affaires ont donc été renvoyées devant la Crown court qui a prononcé des peines de prison. Cet exemple montre que la Cour suprême, comme la Chambre des Lords, est amenée à examiner des questions constitutionnelles dans le cadre de recours ordinaires fondés sur les lois, la common law ou l'equity.

En outre, la Cour suprême peut développer des principes de common law touchant des questions constitutionnelles comme la Chambre des Lords a pu le faire, il y a bien longtemps, dans les affaires dites des interdictions ou des proclamations concernant le statut de la prérogative ordinaire du $\operatorname{Roi}^{200}$ ou plus récemment en interprétant des lois à la lumière de principes constitutionnels de common law. Plusieurs décisions de la Chambre des Lords ont ainsi reconnu l'existence de droits ou libertés constitutionnels sur le fondement desquels des lois ont été interprétées ${ }^{201}$. Si l'entrée en vigueur du $H R A$ réduit l'utilité d'une telle technique, on ne peut exclure le recours à

${ }^{197}$ O. GAY et N. DAVIES, «Impeachment », House of Commons Library, SN/PC/02666, 16 Novembre 2011, disponible sur le site de la Chambre des communes.

${ }^{198}$ A. V. DICEY, Introduction à l'étude du droit constitutionnel, op. cit., p. 172.

${ }^{199} R v$ Chaytor \& Ors [2010] UKSC 52.

${ }^{200}$ The Question of Prohibitions (1607) et The Case of Proclamation (1611). À ce propos, cf. E. ZOLLER, Introduction au droit public, op. cit., pp. 76-77.

${ }^{201}$ Cf. pour ne citer que quelques exemples, Attorney-General v. Times Newspapers [1974] AC 273 ; Anisminic Ltd v Foreign Compensation Commission [1969] 2 AC ; R. v. Secretary of Sate for the Home Department ex parte Leech [1994]QP 198 à propos du droit d'accès au juge ainsi que Cassel and Co Ltd v. Broome [1972] AC 1027 à propos de la liberté d'expression. Pour plus de développement à ce sujet, nous nous permettons de renvoyer à notre thèse A. DUFFY, La protection des droits et libertés au Royaume-Uni. Recherche sur le Human Rights Act 1998 et les mutations du droit constitutionnel britannique face aux exigences de la Convention européenne des droits de l'homme, op. cit., pp. 63-69. 
des principes constitutionnels qui ne seraient pas prévu par cette loi. En se substituant à la garantie des droits et libertés fondée sur la common law le HRA a, comme le EC Act 1972, complété ce contentieux constitutionnel original par un contrôle de constitutionnalité des lois lui aussi spécifique. Le particularisme de ces fonctions constitutionnelles tend néanmoins à décliner en raison du transfert des compétences en matière de dévolution au profit de la Cour suprême.

2. Le contentieux de la dévolution, vecteur direct d'extension des compétences constitutionnelles

Le contentieux de la dévolution développe les fonctions constitutionnelles de cette juridiction constitutionnelle singulière qu'est la Cour suprême. Les lois de dévolution ${ }^{202}$ ont créé une structure territoriale complexe, « quasi-fédérale », pour certains ${ }^{203}$. Elles prévoient un contrôle des actes des entités dévolues qui relève désormais de la compétence de la Cour suprême. Cette dernière est chargée, à l'instar de la Chambre des Lords, d'examiner les «affaires de dévolutions» (devolution matters) ${ }^{204}$. Les caractéristiques des actes susceptibles d'être contrôlés illustrent un transfert de compétences normatives original sur lequel le Parlement de Westminster est libre de revenir. Au pays de Galles, les actes susceptibles d'être concernés par ce contrôle sont des "mesures d'assemblée », qui sont des législations déléguées adoptées par l'Assemblée galloise dans un domaine de compétences défini sur le fondement d'une habilitation des sections 93 et 94 $\mathrm{du}$ Government of Wales Act $2006^{205}$ et des lois de l'Assemblée nationale galloise (Acts of the National Assembly for Wales) ${ }^{206}$, depuis le référendum du 3 mars 2011 qui a étendu les pouvoirs législatifs de l'Assemblée galloise. Le contrôle exercé sur les actes écossais et nord-irlandais porte également sur des « lois» dont la nature est « incertaine ${ }^{207}$. Comme des législations primaires, elles peuvent être sources de législations déléguées et doivent être

${ }^{202}$ À ce sujet, cf. F. ROUX, La dévolution en Grande-Bretagne, Contribution à la réflexion sur l'autonomie institutionnelle, op. cit.

${ }^{203}$ V. BOGDANOR, Devolution in the United Kingdom, Oxford, Oxford University Press, 1999, p. 291.

${ }^{204}$ Section 41(4) du CRA. Sa compétence est prévue par la Section 33 du Scotland Act 1998, les Sections 96, 99 et 112 du Government of Wales Act 2006 et la Section 11 du Northern Ireland Act 1998.

${ }^{205}$ À ce propos, cf. D. BARANGER, Écrire la Constitution non-écrite, coll. «Léviathan », Paris, PUF, 2008, p. 294.

${ }^{206}$ Ces lois ne font pas l'objet du contrôle exercé par le Gouvernement et le Parlement de Westminster sur les mesures d'Assemblée Galloise.

${ }^{207}$ D. BARANGER, Écrire la Constitution non-écrite, op. cit., p. 294. 
«prises en compte par les juridictions » ${ }^{208}$. Comme des législations secondaires, elles sont adoptées sur la base d'une habilitation donnée par le Governement of Wales Act 2006, le Scotland Act 1998 et le Northern Ireland Act $1998^{209}$, au regard de laquelle elles peuvent être contrôlées, et il est toujours possible pour le Parlement de Westminster de continuer à légiférer dans les domaines dévolus.

Dans le contentieux de la dévolution, la Cour suprême peut, d'une part, répondre à une «question ${ }^{210}$ posée par les officiers judiciaires lui demandant si un projet d'acte des entités dévolues respecte bien la répartition des compétences prévue par les lois de dévolution ${ }^{211}$. Il s'agit d'une forme de contrôle a priori facultatif et abstrait ${ }^{212}$. La Cour peut être saisie par les Law officers dans les quatre semaines suivant la première lecture d'un projet de loi gallois, écossais et nord-irlandais ou d'une mesure d'Assemblée, au Pays de Galles, ou bien à tout moment dans les quatre semaines suivant une étape d'approbation d'un projet de loi ou d'une mesure d'Assemblée afin de vérifier que ces textes n'outrepassent pas la compétence législative des entités dévolues. En cas de méconnaissance des principes de répartition des compétences, la décision de la Cour suprême fait obstacle à la promulgation du texte ${ }^{213}$.

La Cour suprême peut, d'autre part, examiner a posteriori et en dernier ressort des «devolution issues » en vertu de la section 41(4)(b) du CRA. Ces questions consistent à vérifier que les actes des Assemblées et des Exécutifs dévolus relèvent bien des compétences prévues par les lois de dévolution et respectent tant le droit de l'Union européenne que le droit de la Convention européenne de sauvegarde des droits de l'homme et des libertés fondamentales $^{214}$. Ces actes seront écartés s'ils violent les lois de dévolution, le droit communautaire ou les droits conventionnels ${ }^{215}$. Le contentieux de la

\footnotetext{
${ }^{208}$ Cette obligation existe en vertu des Sections 107(4) du GWA et 28(6) du SA. Cette «formule [...] indique que les juridictions sont dans l'obligation d'appliquer ces textes, sans pouvoir en contrôler la validité et éventuellement les annuler ». Ibid.

${ }^{209}$ Sections 107 et 108 du GWA, Sections 28 et 29 du SA, Sections 5 et 6 du NIA.

${ }^{210}$ Art. 41(4)(a) du CRA. Le contrôle peut être déclenché par le Conseiller général gallois ; 1'Attorney General d'Angleterre et du Pays de Galles (Section 99 et 112 du GWA); par l'Advocate General pour l'Écosse, le Lord Advocate écossais (Section 33 du SA) ainsi que l'Attorney General en Irlande du Nord (Section 11 du NIA). L'Advocate General pour l'Écosse est un ministre de la Couronne et l'un des trois Conseillers juridiques britanniques au même rang que l'Attorney General et le Solicitor General pour l'Angleterre et l'Irlande du Nord. Le Lord Advocate écossais est le Conseiller juridique du Gouvernement écossais et de la Couronne en Écosse.

${ }^{211}$ Section 41 (4) (a) du CRA.

${ }^{212}$ À ce propos, cf. V. BOGDANOR, Devolution in the United Kingdom, OUP, 1999, p. 206.

${ }^{213}$ Sections 94(2) et 108(2) du GWA, Sectios 29(1) du SA et 6(1) du NIA.

${ }^{214}$ Ces litiges sont détaillés dans l'annexe 9 du GWA, dans l'annexe $6 \mathrm{du} S A$ ou dans l'annexe $10 \mathrm{du}$ NIA. À ce propos, cf. F. ROUX, La dévolution en Grande-Bretagne, Contribution à la réflexion sur l'autonomie institutionnelle, op. cit., pp. 188-200.

${ }^{215}$ Lord Hope of Craighead, « The Reform of the House of Lords », RIDC n 2-2008, p. 262.
} 
dévolution présente donc certaines spécificités par rapport au contentieux territorial d'autres systèmes car il ne se limite pas au seul contrôle de la répartition des compétences normatives entre territoires, mais présente aussi une dimension européenne. La Cour suprême peut être saisie de ces devolution issues de façon différente ${ }^{216}$. Les Law officers, partis à l'instance, peuvent demander à n'importe quelle juridiction de renvoyer une question de dévolution à la Cour suprême. Sinon, certaines juridictions ${ }^{217}$ sont tenues de renvoyer les questions de dévolution dont elles sont saisies à une Cour supérieure en Écosse, au Pays de Galles ou en Irlande du Nord, qui pourra ensuite saisir la Cour suprême par la voie de l'appel. Cette dernière, compétente en dernier ressort, pourra déclarer l'acte ultra vires s'il ne respecte pas les règles de compétences prévues par les lois de dévolution ${ }^{218}$. Les décisions peuvent avoir, selon la nature de l'acte contesté (un acte d'une assemblée dévolue ou l'exercice d'une fonction par un exécutif dévolu), les griefs invoqués contre cet acte (contrariété à la répartition des compétences organisée par les lois de dévolution, contrariété au droit communautaire ou contrariété aux droits conventionnels) une autorité variable. Cette autorité est, en principe, relative. Néanmoins, la décision aura, en pratique, une autorité absolue si la contrariété d'un acte législatif d'une entité dévolue avec l'organisation de la répartition des compétences par les lois de dévolution est constatée par la Cour suprême, ce qui n'a pour l'instant jamais eu lieu. Le contentieux de la dévolution a, en effet, été dominé par le contrôle du respect des droits de la CEDH et la seule décision à s'être prononcée exclusivement sur une question la méconnaissance des règles de répartition des compétences n'a pas déclaré illégale la loi pénale écossaise en cause dans cette affaire ${ }^{219}$.

Les contrôles normatifs et de répartition des compétences exercés par la Cour suprême dans le cadre de ce contentieux «quasi-fédéral » ${ }^{220}$ s'apparentent ainsi au contentieux des compétences territoriales que l'on retrouve devant certaines Cours suprêmes ou constitutionnelles ${ }^{221}$. Ces

${ }^{216}$ À ce propos, cf. P. LAUVAUX, Les grandes démocraties contemporaines, Paris, PUF, 2004, pp. 491-492.

${ }^{217}$ La nature de ces juridictions est prévue par les annexes 6, 9 et $10 \mathrm{du}$ SA, GWA et NIA.

${ }^{218}$ Section 29 du Scotland Act 1998, Section 6 du Northern Irland Act 1998, Sections 94 et 108 du Governement of Wales Act 2005.

${ }^{219}$ Martin v Her Majesty's Advocate (Scotland); Miller v Her Majesty's Advocate (Scotland) [2010] UKSC 10.

${ }^{220}$ V. BOGDANOR, Devolution in the United Kingdom, Oxford, Oxford University Press, 1999, p. 291 ou R. HAZELL, « Reinventing the Constitution : Can the State survive ? », PL, 1999, p. 92.

${ }^{221}$ Ce type de contentieux est, par exemple, présent dans des États fédéraux devant la Cour suprême des États-Unis (art. III, section 2 [1] de la Constitution des États-Unis), du Canada (art. 35.1 de la Loi sur la Cour suprême (L.R.C. (1985))), de l'Inde (art. 131 de la Constitution indienne) ou devant la Cour constitutionnelle en Allemagne (art. 93(1) de la Loi fondamentale), en Autriche 
compétences présentent une originalité par rapport aux compétences de Cours suprêmes intervenant dans des systèmes fédéraux en raison de leur caractère 《asymétrique $»^{222}$. Elles ne contraignent que la périphérie et non le centre. Le Parlement de Westminster peut toujours revenir sur les compétences dévolues $^{223}$ et ne peut voir ses lois annulées ou écartées pour violation des règles de répartition des compétences. Toujours est-il qu'en examinant les actes des entités dévolues, la Cour suprême, à l'instar du Privy Council, dispose de «fonctions d'une Cour constitutionnelle pour les questions de dévolution ${ }^{224}$. D'ailleurs, lors de l'adoption des lois de dévolution, le Gouvernement s'était orienté vers l'attribution de cette compétence au Privy Council car il estimait que cette juridiction dotée de «l'expérience d'une Cour suprême constitutionnelle pour les différentes dépendances et colonies du Commonwealth ${ }^{225}$. La Cour suprême du Royaume-Uni, exerce ainsi un « contrôle constitutionnel de la dévolution » ${ }^{226}$ ou un "contrôle localisé de constitutionnalité ${ }^{227}$, qui a considérablement développé le champ de ses compétences constitutionnelles et de dernier ressort.

Cette fonction pourrait, par ailleurs, avoir des conséquences plus larges. Des observateurs aussi avisés que le juge de la Cour suprême américaine Sandra Day O'Connor estiment que si ce contentieux tendait à prendre plus d'ampleur, il pourrait conduire la Cour suprême à généraliser et approfondir son approche en matière de contrôle des lois dans d'autres domaines ${ }^{228}$. Une telle évolution n'est pas encore à l'ordre du jour et les convergences constatées avec d'autres Cours suprêmes dotées de compétences constitutionnelles ne gomment pour l'instant pas la spécificité des compétences de dernier ressort et constitutionnelles de la Cour suprême au Royaume-Uni. L'institution de cette juridiction consolide ainsi des mutations

(art. 138, 126a et 148f de la Constitution) ou encore, dans des États régionaux, en Espagne (art. 1611 de la Constitution) et en Italie (art. 134 de la Constitution) pour ne citer que quelques exemples.

${ }^{222}$ P. LAUVAUX, Les grandes démocraties contemporaines, op. cit., p. 493.

${ }^{223}$ Section 28(7) du SA, Section 93(5) et 105(5) du GWA, Section 5(6) du NIA.

${ }^{224}$ V. BOGDANOR, Devolution in the United Kingdom, Oxford University Press, 1999, p. 206 ; cf. également N. WALKER, «Final Appellate Jurisdiction in the Scottish Legal System », January 2010, § 3.4 disponible sur le site du gouvernement écossais.

${ }_{225}$ Lord Irvine, Hansard, HL, 28 October 1998, col. 1983. En outre, un certain nombre d'amendements avaient, au cours des débats à propos des projets de lois de dévolution écossaise et galloise, proposé la création d'une cour constitutionnelle pour examiner les questions de répartition de compétence. Hansard, HL, col. 1963, 28 October 1998 ; Hansard, HC, col. 204, 12 May 1998.

${ }^{226}$ F. ROUX, La dévolution en Grande-Bretagne, Contribution à la réflexion sur l'autonomie institutionnelle, op. cit., p. 186.

${ }^{227}$ V. CONSTANTINESCO, S. PIERRÉ CAPS, Droit constitutionnel, coll. « Thémis », PUF, 2011, p. 58.

${ }^{228}$ Sandra DAY O'CONNOR J., "Altered States: Federalism and Devolution at the 'Real' Turn of the Millennium », CLJ, 2001, p. 498. 
antérieures du constitutionnalisme britannique. Ces mutations devront, pour parfaire la nature de la Cour suprême, nécessairement être approfondies.

\section{C. - Les conditions de la métamorphose définitive de la Cour suprême}

Les attributions de la Cour suprême influencent les fondements de la Constitution du Royaume-Uni. Par ses compétences et sa jurisprudence, la Cour suprême perpétue la consolidation du principe de Rule of Law, précédemment amorcée par la Chambre des Lords, par rapport à un principe de souveraineté parlementaire dont le déclin se poursuit. Le véritable changement de nature de la Cour dépend de l'interprétation qu'elle fera de ces deux fondements de la Constitution du Royaume-Uni. Sa métamorphose définitive est conditionnée par la remise en cause du principe de souveraineté parlementaire.

\section{La consolidation du principe de Rule of Law}

Analyser le rôle de la Cour suprême par rapport au principe de Rule of Law nécessite d'abord de comprendre la Constitution britannique telle que l'a présenté A. V. Dicey, à savoir, une «Constitution faite par les juges ( $a$ judge-made Constitution) ${ }^{229}$. Comme il l'explique, en présentant le principe de Rule of Law, " le règne de la loi pénètre dans la Constitution pour cette raison que les principes généraux de la Constitution (tel que, par exemple, le droit à la liberté individuelle et le droit de réunion publique) sont chez nous le résultat des décisions judiciaires déterminant les droits de simples citoyens dans les cas particuliers soumis à l'appréciation des tribunaux; au contraire, sous l'empire de beaucoup de Constitutions étrangères, la garantie (telle qu'elle existe) accordée aux droits des individus résulte ou semble résulter des principes généraux de la Constitution ${ }^{230}$. Il conclut sur ce point en indiquant que «le terme, le « règne de la loi », peut être employé comme exprimant le fait que le droit constitutionnel anglais, c'est-à-dire les règles qui, à l'étranger font naturellement partie d'un Code constitutionnel, ne sont pas la source, mais la conséquence des droits des particuliers, définis et sanctionnés par les tribunaux; bref, que les principes du droit privé ont été étendus en Angleterre par l'action des tribunaux et de la Couronne et de ses fonctionnaires ; ainsi, la Constitution est le résultat de la loi ordinaire du pays ${ }^{231}$. Si l'on suit ce raisonnement, chaque décision de la Cour suprême à l'instar de celles de la Chambre des Lords, contribue au

\footnotetext{
${ }^{229}$ A. V. DICEY, Introduction à l'étude du droit constitutionnel, op. cit., p. 175.

${ }^{230}$ Ibid., p. 174

${ }^{231}$ Ibid., p. 181
} 
développement de cette "Constitution faite par les juges » sous-tendue par le principe ubi jus, ibi remedium ${ }^{232}$, élément indissociable de la Rule of Law. L'affirmation du principe de Rule of Law à la suite du CRA résulte, en outre, de plusieurs autres facteurs.

La consécration textuelle de ce principe dans la première section de la loi sur la réforme constitutionnelle et l'omission de toute référence au principe de souveraineté Parlementaire conforte, tout d'abord, l'importance croissante de la Rule of Law. Le soin avec lequel le législateur précise que le $C R A$ n'affecte pas défavorablement le principe constitutionnel de Rule of $L a w^{233}$ illustre sa volonté d'ancrer ce principe dans le droit positif écrit et de prévenir toute déstabilisation de ce fondement de la Constitution britannique au cœur duquel se trouve le rôle du juge. Elle s'inscrit en ce sens dans un mouvement de consolidation de la Rule of Law qui a précédé la mise en place de la Cour suprême puisque certains Law Lords ont reconnu un affaiblissement de l'autorité du principe de souveraineté du Parlement corrélatif à l'affirmation du principe de Rule of Law dans la décision Jackson du 13 octobre $2005^{234}$. Lord Hope affirme ainsi que «le principe de souveraineté parlementaire n'est plus, s'il l'a jamais été, absolu » et reconnaît que « la rule of law, mise en œuvre par les cours, est le facteur ultime de contrôle sur lequel [la] Constitution est fondée ${ }^{235}$.

Le $C R A$ s'inscrit, ensuite, dans une dynamique générale d'affirmation du principe de Rule of Law par l'attribution de compétences en matière de dévolution, qui donne à la Cour suprême l'occasion d'être saisie de nouveaux recours et de reconnaître par là même de nouveaux droits, tels que la présence d'un avocat pendant une garde à vue ${ }^{236}$, par exemple.

Par ailleurs, en la mettant formellement en valeur, le $C R A$ a amélioré la perception de la plus haute juridiction britannique et a donné, selon certains Justice, tel Lord Hope, une nouvelle autorité à ses décisions ${ }^{237}$. En rendant plus visible la Cour suprême, le CRA affirme son rôle et celui de sa

${ }^{232}$ Il indique qu' « En ce qui touche le droit constitutionnel, cet axiome [ubi jus, ibi remedium] signifie que les Anglais [...] - s'attachèrent beaucoup plus volontiers à trouver des remèdes pour garantir les droits individuels, ou [...] à prévenir des maux définis, qu'à rédiger une déclaration des Droits de l'homme ou des Droits des Anglais », ibid., pp. 177-178.

${ }^{233}$ Section 1 du CRA: «Cette loi n'affecte pas défavorablement (a) le principe constitutionnel existant de rule of law, ou (b) le rôle constitutionnel existant du Lord Chancelier à l'égard de ce principe ».

${ }^{234} R$ (Jackson) v Her Majesty's Attorney-General [2005] UKHL 56. À ce propos, cf. T. GUILLUY, « Le Parliament Act de 1911 a-t-il intronisé un nouveau souverain ? Réflexions sur la décision Jackson », Jus Politicum, n 6, 2011, http://www.juspoliticum.com/Le-ParliamentAct-de-1911-a-t-il.html.

${ }^{235}$ Ibid. $\$ .104$ et 107. exemple.

${ }^{236}$ Cadder v Her Majesty's Advocate (Scotland) [2010] UKSC 43, pour ne citer qu'un

${ }^{237}$ Lord Hope, « The creation of a supreme Court, Was it Worth It », op. cit., p. 5. 
jurisprudence. La Cour suprême symbolise ainsi la garantie juridictionnelle ultime du principe de Rule of Law qui implique, outre le principe de légalité et d'égalité devant la loi, un principe de protection judiciaire des droits qui est clairement mis en avant, notamment dans les rapports annuels de la Cour $^{238}$. La reconnaissance de tels droits est effectuée par l'intermédiaire de recours fondés sur la common law, l'equity, des lois ordinaires ou constitutionnelles telles que le HRA. La Cour suprême a, par exemple, reconnu de nouveaux droits à des enfants dont la garde était en cause en jugeant qu'une attention particulière devait être accordée à leur bien être, ce qui pouvait impliquer que celui-ci soit gardé par sa grand-mère maternelle plutôt que par son père biologique ${ }^{239}$. Une protection plus étendue a été accordée aux victimes de violences domestiques puisque la Cour suprême a interprété le terme violence domestique mentionné dans la section 177(1) du Housing Act 1996 dans un sens large allant au-delà des violences physiques $^{240}$. La politique d'admission d'un établissement scolaire juif a été jugée contraire à l'interdiction des discriminations fondées sur les origines ethniques prévue par la section 1 du Race Relations Ac 1976 car elle imposait que les élèves soient juifs en raison d'une descendance maternelle ou après avoir effectué une conversion orthodoxe $\mathrm{e}^{241}$. Par ailleurs, la protection judiciaire des droits, essentiellement assurée par le $H R A$, marque une évolution de la conception Diceyenne du principe de Rule of Law supposant à l'origine l'absence de déclaration de droits. Le Human Rights Act, substitut d'une déclaration de droits, est à l'origine d'un nombre croissant de décisions. Par la place qu'elle donne au sein de son contentieux à la question des droits de l'homme incorporés par le $H R A$, la Cour suprême à la suite de l'Appellate Committee de la Chambre des Lords, montre que la Constitution britannique n'est plus exclusivement le résultat des décisions des juges britanniques, mais s'est familiarisée avec l'idée d'une déclaration de droits plus connue des Constitutions rigides. Elle témoigne en ce sens d'une véritable mutation du principe de Rule of Law.

La concentration des compétences pour juger en dernier ressort de tous types de contentieux contribue à faire de la Cour suprême le juge privilégié de cette «judge-made Constitution» et affermit en ce sens la Rule of Law. Ce principe, dont l'existence en Amérique avait également été relevée par Tocqueville ${ }^{242}$, renvoie au «goût pour la justice» et à la «place que les

\footnotetext{
${ }^{238}$ La grande majorité des décisions présentées dans les rapports annuels sont des décisions portant sur les droits et libertés. Cf. à ce sujet, les rapports publiés sur le site de la Cour suprême.

${ }^{239}$ In Re B (A Child) [2009] UKSC 5.

${ }^{240}$ Yemshaw $v$ London Borough of Hounslow [2011] UKSC 3.

${ }^{241} R$ (on the application of E) $v$ The Governing Body of JFS \& Others [2009] UKSC 15.

${ }^{242}$ A. de TOCQUEVILLE, De la démocratie en Amérique, I, II, viii, in CEuvres, vol. II, coll. « Bibliothèque de la Pléiade », Gallimard, 1991, pp. 302-303, cité par E. ZOLLER, Introduction au droit public, op. cit., p. 97.
} 
tribunaux occupent dans l'opinion publique à côté des rouages politiques ${ }^{243}$. L'essence de ce principe, commune à ces deux systèmes, repose sur le rôle du juge chargé d'assurer cette «prééminence du droit» ${ }^{244}$. Alors qu'aux ÉtatsUnis cette prééminence du droit est entendue comme le droit de la Constitution et s'impose au législateur, elle doit, au Royaume-Uni, être conciliée avec la souveraineté du Parlement qui connaît cependant une érosion progressive.

\section{La remise en cause du principe de souveraineté parlementaire}

Vecteur de consolidation de la Rule of Law, le CRA donne-t-il à la Cour suprême les moyens de remettre en cause le principe de souveraineté parlementaire ? Ouvre-t-il la porte à une forme plus accomplie de contrôle de constitutionnalité des lois et par là-même à l'existence d'une Cour suprême plus aboutie ? En effet, la compétence de dernier ressort de la Cour connaît des écueils notamment en raison de l'absence de compétence pour le contentieux pénal écossais, ce qui est cependant partiellement compensé par la pratique juridictionnelle en matière de dévolution. L'absence de contrôle complet de constitutionnalité des lois et, par extension le principe de souveraineté du Parlement, constitue un obstacle plus difficile à surmonter afin de pouvoir pleinement assimiler la Cour suprême du Royaume-Uni à ses homologues américaine, canadienne, indienne disposant d'une telle compétence.

L'existence et la substance du principe de souveraineté parlementaire sont fondées sur la common law $^{245}$ à tel point que certains auteurs parlent de constitutionnalisme de common law. J. Goldworthy, pourtant opposé à cette conception du droit britannique, a résumé cette doctrine dans les termes suivants « La Constitution britannique non écrite consiste en des principes de common law et par conséquent l'autorité du Parlement pour adopter des lois découle de la common law ${ }^{246}$. Les opinions de certains Lords semblent

${ }^{243}$ A. de TOCQUEVILLE, Voyage en Suisse, in Fuvre, vol. I, coll. «Bibliothèque de la Pléiade », Gallimard, 1991, p. 619 cité par E. ZOLLER, Introduction au droit public, op. cit., p. 97.

${ }^{244}$ E. ZOLLER, Introduction au droit public, op. cit., p. 97.

245 À ce sujet, cf. D. BARANGER, "Angleterre "Culture juridique" ", in S. RIALS, D. ALLAND (dir.), Dictionnaire de la culture juridique, Paris, PUF, 2003, p. 58 et E. ZOLLER, Introduction au droit public, op. cit., p. 90. Pour une reprise des différentes théories en présence, cf. H. MUIR-WATT, «Le problème du «constitutional review » : le modèle du Royaume-Uni », CCC, 2008, ${ }^{\circ}$ 24, pp. 94-97 ; cf. également Thoburn v. Sunderland City Council, op. cit., § 59-60.

${ }^{246}$ J. GOLDSWORTHY, The Myth of the Common Law Constitution, in EDLIN (ed.), Common Law Theory, Cambridge, 2007, p. 204 cité dans Sir Anthony CLARK, « Constitutional Justice : Lessons form Magna Carta », Royal Holloway University of London, Surrey, 16 June 2008, p. 10. Le plus fervent défenseur de la théorie du constitutionalisme de common law est T.R.S Allan, " The Common Law as Constitution : Fundamental Rights and First Principles », in C. SAUNDERS (ed.), Courts of Final Jurisdiction: the Mason Court in Australia, Federation Press, 1996, pp. 146166. 
aller dans ce sens. Dans la décision Jackson, Lord Steyn a ainsi avancé, à propos de la souveraineté du Parlement, qu'il «s'agit d'une construction de la common law. Les juges ont créé ce principe $»^{247}$.

Quelle est alors la portée de l'établissement de la Cour suprême, dont dépend en dernier ressort l'interprétation et l'application de la common law, sur les différentes composantes du principe de souveraineté parlementaire? L'impossibilité pour le Parlement de lier ses successeurs et l'interdiction d'annuler ou d'écarter une loi, ont déjà été remises en cause, à des degrés différents. L'érosion progressive de ce principe résulte de ce que des lois telles que le European Communities Act 1972, le HRA et les lois de dévolution ont invité le juge à exercer une forme originale de contrôle des lois. La souveraineté du Parlement est, en quelque sorte, contrainte «par le haut» et «par le bas » ${ }^{248}$ en raison du contrôle des lois exercé sur le fondement de ces lois constitutionnelles qui se distinguent formellement des lois ordinaires, à la suite de l'arrêt Thoburn ${ }^{249}$. Le dernier aspect du principe de souveraineté parlementaire qui concerne l'absence de hiérarchie entre lois, a également été fragilisé par cet arrêt avant le $C R A$.

La concentration de cette double contrainte au sein d'une seule et même institution, alors qu'elle était autrefois répartie entre la Chambre des Lords et le Privy Council, conforte l'idée d'un contre-pouvoir juridictionnel renforcé face au Parlement souverain. La Cour suprême ira-t-elle bientôt au bout de la logique de ce contrôle en adoptant un contrôle de constitutionnalité complet par un Marbury v. Madison ${ }^{250}$ à l'anglaise ? En effet, ces attributions pourraient avoir donné à la nouvelle Cour suprême un «avant goût» de ce que peuvent faire les juridictions constitutionnelles. Comme le souligne Lord Neuberger of Abbotsbury, la section 40 (5) du CRA pourrait constituer le fondement d'un pouvoir de contrôle de constitutionnalité des lois puisqu'elle dispose que la Cour suprême «a le pouvoir de régler toute question nécessaire à la détermination de la justice lorsqu'un appel est porté devant elle sur le fondement de toute loi ». Le Master of the Rolls suggère que si la question de la contrariété d'une loi à un «droit fondamental, un droit constitutionnel » se posait, la section 40(5) pourrait légitimement être interprétée comme autorisant un contrôle de constitutionnalité des lois $^{251}$. Une telle perspective est-elle envisageable ?

\footnotetext{
${ }^{247} R$ (Jackson) v. Her Majesty's Attorney-General [2005] UKHL 56, § 102.

${ }^{248}$ Pour reprendre l'image du Pr. R. HAZELL, «Westminster Squeezed from Above and Below ", in R. HAZELL (dir.), Constitutional Futures : A History of the Next Ten Years, Oxford/New York, Oxford University Press, 1999, pp. 111-135.

${ }^{249}$ [2002] EWHC 195, [2002] 3 WLR 247.

250 Marbury v. Madison 5 U.S. (1 Cranch) 137 (24 févr. 1809).

${ }^{251}$ Lord Neuberger of Abbotsbury, «The Supreme Court: Is the House of Lords "Losing part of Itself"? », The Young legal Group of the British Friends of the Hebrew University Lecture, 2 december 2009, p. 11.
} 
Le principe de souveraineté parlementaire est censé y faire obstacle. Néanmoins, ce principe dépend essentiellement de la volonté des juges et notamment de ceux de la Cour suprême, puisque l'on se situe dans le cadre d'une «judge-made Constitution» et qu'il est, par ailleurs, difficile d'envisager en théorie comme en pratique que le Parlement souverain renonce à sa propre souveraineté. En conséquence, la remise en cause définitive du principe de souveraineté du Parlement dépend de l'attachement dont font preuve les juridictions britanniques, au premier rang desquelles la Cour suprême, à son égard. Il pourrait ainsi être redéfini par les juges sur la base d'une nouvelle théorie constitutionnelle amorcée dans la décision $J_{a c k s o n}{ }^{252}$. Lord Steyn y a affirmé que « la doctrine de la suprématie pure et absolue de la souveraineté du Parlement n'a plus sa place dans le RoyaumeUni moderne ». Il ajoute que « Si tel est le cas il n'est pas impensable que des circonstances puissent conduire les Cours à reconnaître un principe établi sur une théorie différente de constitutionnalisme $»^{253}$. Lady Hale a, pour sa part, suggéré que, dans des circonstances exceptionnelles, une loi qui détruirait le principe de Rule of law en "empêchant tout contrôle juridictionnel des actions du gouvernement affectant les droits des individus $»^{254}$ pourrait être contrôlée par les Cours.

Si la Cour suprême devait emprunter cette voie, il faudrait qu'elle interprète différemment le principe de Rule of Law puisque le principe de souveraineté parlementaire est « la conséquence et non la cause du principe de la rule of law ${ }^{255}$. La Cour suprême pourrait, en reprenant, la portée de l'arrêt Thoburn, déduire de la Rule of Law l'existence d'un nouveau recours en inconstitutionnalité sur la base des certaines lois « constitutionnelles» ou de principes constitutionnels de common law prévalant sur les autres lois ou principes de common law. Le renforcement du principe de Rule of Law rendrait ainsi envisageable de nouveaux recours à travers une forme plus aboutie de contrôle de constitutionnalité. Dans une telle hypothèse, la Rule of Law telle qu'elle a été transformée par la pratique constitutionnelle et juridictionnelle américaine qui correspond à l'idée de prééminence du droit de la Constitution s'imposant à tous les pouvoirs reviendrait, par la «porte de service », sous une forme atténuée au Royaume-Uni. À défaut de pouvoir l'établir en adoptant une Constitution rigide prévoyant un tel contrôle de constitutionnalité, une telle interprétation ouvrirait la voie à la garantie juridictionnelle d'une Constitution toujours emprunte d'originalité en raison

${ }^{252} \grave{A}$ ce sujet, cf. J. JOWELL, «Parliament Sovereignty under the new Constitutional hypothesis ", $P L, 2006$, pp. 562-580.

${ }^{253} R$ (Jackson) v Her Majesty's Attorney-General [2005] UKHL 56, § 102.

${ }^{254}$ Ibid., $\$ 159$

${ }^{255}$ E. ZOLLER, Introduction au droit public, op. cit., p. 90. 
du maintien de ses divers fondements (common law, lois et conventions constitutionnelles), mais partiellement formalisée.

Cette interprétation du principe de Rule of Law conduisant à une remise en cause définitive de la souveraineté du Parlement ne semble pour l'instant pas être partagée par l'actuel Président de la Cour suprême, Lord Phillips, à l'instar de l'ancien Président de la Chambre des Lords, Lord Bingham ${ }^{256}$. Les décisions de la Cour suprême révèlent d'ailleurs une certaine déférence à l'égard du Parlement qui ne laisse pas augurer l'imminence d'un tel changement ${ }^{257}$. Le Royaume-Uni ne franchira le Rubicon qui le sépare encore des autres Cours suprêmes dotées de fonctions constitutionnelles qu'à condition que le principe de Rule of Law nouvellement interprété l'emporte sur la Souveraineté du Parlement. En définitive, l'ultime transformation de la Cour suprême ne dépend que d'elle.

La Cour suprême du Royaume-Uni a été instaurée dans une phase de transition du constitutionnalisme britannique. Elle conforte, au niveau juridictionnel, des évolutions constitutionnelles, mais ne constitue pas, en elle-même, un véritable bouleversement. Corrélativement à l'écriture progressive de la Constitution britannique, le juge a vu son rôle renforcé face au Parlement. La Cour suprême prend ainsi acte, d'évolutions institutionnelles et normatives en héritant notamment d'un contentieux normatif de dimension régionale et d'un contrôle des lois de Westminter par rapport au droit européen qui s'apparente à une forme originale de contrôle de constitutionnalité. Le CRA a accru les convergences formelles et fonctionnelles avec d'autres Cours suprêmes, dont certaines manifestations existaient déjà à l'époque de la Chambre des Lords. Il n'a cependant pas effacé la nature atypique de cette juridiction qui emprunte à la notion de juridiction suprême et constitutionnelle sans y correspondre exactement.

L'expérience britannique trouve, de par ces convergences, toute sa place au sein de la comparaison entre systèmes de justice constitutionnelle. Cette juridiction atypique témoigne des limites d'une conception restrictive de la notion de justice constitutionnelle et de sa modélisation. Ses compétences présentent, en effet, des caractéristiques qui n'entrent pas dans

${ }^{256}$ À ce propos, cf. Lord Neuberger of Abbotsbury, «The Supreme Court: Is the House of Lords "Losing part of Itself"? », op. cit., p. 11.

${ }^{257}$ Cf., par ex., Al Rawi \& Ors v. The Security Service \& Ors [2011] UKSC 34 dans laquelle la Cour suprême a récemment jugé qu'elles n'avaient aucun pouvoir pour remplacer la procédure de présentation de preuves basée sur la règle de common law de "public interest immunity " permettant d'exclure un certain nombre de preuves au nom de l'intérêt public, par une procédure de «closed material » limitant la connaissance des éléments de preuves cachées à un avocat spécialisé. Ce pouvoir revient, selon elle, au Parlement. 
la classification entre modèle américain et européen, ni dans aucune autre classification $^{258}$. Les compétences de la Cour suprême ne sont pas fondées sur une Constitution rigide, mais sur la common law ou des lois «constitutionnelles» originales dont certaines incorporent des traités européens. Le contentieux qui naît de l'application de ces règles constitutionnelles n'est, ni concentré, ni totalement diffus puisque les juridictions compétentes varient selon le litige dont il est question. Si toutes les juridictions sont habilitées à contrôler les actes par rapport au droit de l'Union européenne ou encore à juger, selon les règles de droit commun, des actes des membres du Parlement ou du Gouvernement, le contentieux de dévolution et du HRA en cas de déclaration d'incompatibilité tend à se concentrer puisqu'il appartient aux plus Hautes juridictions. Le contentieux constitutionnel est, en dehors des questions de dévolution contrôlées $a$ priori, essentiellement exercé $a$ posteriori et présente un caractère concret étant résolu par le juge saisi du litige. Ce contentieux est, par ailleurs, essentiellement exercé par voie d'exception puisque les questions constitutionnelles ne sont pas, à l'exception du contentieux a priori de la dévolution, l'objet même du recours et sont accessoires à un litige dont elles permettent la résolution. Enfin, l'effet des décisions est variable. En principe, les décisions ont un effet inter partes, qui est limité, en pratique, par la règle du précédent. En revanche, les décisions prononçant des déclarations d'incompatibilité sur la base du HRA ont une autorité politique en raison de leur absence d'effet juridique sur la loi en cause et de l'invitation qu'elles formulent à l'attention du législateur pour la modifier. D'ailleurs, si les déclarations d'inconstitutionnalité avec effet différé prononcées notamment dans des décisions QPC en France ${ }^{259}$ ont un effet abrogatif, le report dans le temps de cette abrogation qui fait obstacle à la disparition immédiate d'une inconstitutionnalité et l'invitation qu'elles

\footnotetext{
${ }^{258}$ Certaines autres propositions opposent les modèles centrés sur la constitutionnalité de la loi et les modèles centrés sur les droits fondamentaux (F. RUBIO LORENTE, « Tendances actuelles de la juridiction constitutionnelle en Europe », AIJC, 1996, pp. 11-29) ou encore celle opposant contrôle abstrait et contrôle concret (M. FROMONT, La justice constitutionnelle dans le monde, coll. «Connaissance du droit», Dalloz, 1996, p. 41. À propos de la présentation de ces modélisations, cf. G. TUSSEAU, Contre les «modèles » de Justice constitutionnelle: essai de critique méthodologique - Modelli di giustizia costituzionale : saggion di critica metodologica, op. cit., pp. 71-77.

${ }^{259}$ Cf. pour ne prendre qu'un exemple parmi d'autres, Cons. const., décision n ${ }^{\circ} 2010-1$ QPC du 28 mai 2010, Consorts L., JO du 29 mai 2010, p. 9728. Les Cours constitutionnelles européennes ont tendance à prononcer des décisions déclaratives et peuvent également reporter les effets de celles-ci dans le temps. Cf. la décision d'inconstitutionnalité et non de nullité du Tribunal constitutionnel Espagnol, 20 févr. 1989, $\mathrm{n}^{\circ}$ 45/1989, BOE $\mathrm{n}^{\circ} 52$ du 2 mars 1989 commentée in P. BON et D. MAUS, Les grandes décisions des cours constitutionnelles européennes, Dalloz, 2008, p. 767. Ces éléments montrent bien que ce paramètre d'annulation et/ou de non-application n'est pas décisif pour écarter une juridiction de la qualification de juridiction constitutionnelle.
} 
formulent à l'égard du législateur pour corriger l'inconstitutionnalité dénoncée ne font-ils pas, dans une certaine mesure, écho à la procédure britannique ? En revanche, au Royaume-Uni, une décision dans laquelle la déclaration d'incompatibilité est formulée aura également un effet inter partes et non erga omnes lorsqu'elle se prononce sur les autres demandes du requérant ${ }^{260}$. Le contentieux constitutionnel exercé par la Cour suprême au Royaume-Uni revêt donc les caractéristiques d'un contrôle partiellement diffus, essentiellement concret, exercé a posteriori, par voie d'exception qui est à l'origine de décisions dotées d'une autorité de chose jugée variable. Cette coexistence entre caractéristiques et les nuances dont elles témoignent existe dans bon nombre d'autres systèmes ${ }^{261}$. La Cour suprême confirme ainsi les limites des classifications qui ne couvrent pas l'ensemble des réalités institutionnelles que 1 'on rencontre en droit positif ${ }^{262}$. Les caractéristiques du contentieux constitutionnel devant la Cour suprême confortent le caractère atypique de cette juridiction dont les compétences constitutionnelles et de dernier ressort se sont néanmoins développées, favorisant une convergence encore plus accrue avec d'autres Cours suprêmes.

Elle ne correspond en effet, mais comme bien d'autres juridictions, à aucune classification et appelle à penser autrement la justice constitutionnelle. La Cour suprême au Royaume-Uni montre, à l'instar de l'expérience israélienne ${ }^{263}$, que la notion de juge et de justice constitutionnelle n'est pas inconciliable avec celle de Constitution souple et révèle la nécessité d'appréhender plus largement cette notion. Bien qu'il confirme la nature hors norme de la plus haute juridiction britannique, le $C R A$ démontre néanmoins qu'elle assure, comme l'Appellate Committee de la Chambre des Lords, une forme de justice constitutionnelle en raison de l'existence d'un "garantie

${ }^{260}$ Cf. par ex. en Irlande la décision McR, Re an Application for Judicial Review [2002] NIQB 58 dans laquelle la Haute Cour de justice a prononcé une déclaration d'incompatibilité de la Section 62 de l'Offences Against the Person Act 1861et a ensuite accordé le certiorari au requérant. Cf. également, la décision William Smith (Assisted Person) v. K.D. Scott, Electoral Registration Officer for the areas of Clackmannanshire, Falkirk and Stirling [2007] CSIH 9, Registration Appeal Court dans laquelle la Cour a prononcé une déclaration d'incompatibilité de la Section 3(1) du Representation of the People Act 1983 tout en refusant l'appel.

${ }^{261}$ Pour une présentation synthétique des "problèmes empiriques » posés par la modélisation des systèmes de justice constitutionnelle cf. G. TUSSEAU, Contre les "modèles " de Justice constitutionnelle : essai de critique méthodologique - Modelli di giustizia costituzionale : saggion di critica metodologica, op. cit., pp. 25-50.

${ }^{262}$ À cet égard, ibid., p. 25.

${ }^{263}$ À ce propos, cf. not. E. MARCOVICI, « Soixante ans après : Israël doit-il toujours se doter d'une Constitution ?», RDP, 2009, n 1, p. 125 ; A. JUSSIAUME, «La Cour suprême et la Constitution en Israël: Entre activisme et prudence judiciaire», Jus Politicum, n ${ }^{\circ} 3,2009$, http://www.juspoliticum.com/La-Cour-supreme-et-la-Constitution.html. 
juridictionnelle », certes originale, « de la Constitution » du Royaume-Uni ${ }^{264}$. La Cour suprême enrichit ainsi les systèmes de justice constitutionnelle d'une nouvelle forme de juridiction à la croisée des chemins et témoigne de leur diversité. En définitive, puisqu'un système dispose de la justice constitutionnelle dessinée par sa Constitution ${ }^{265}$, celle du Royaume-Uni faisant l'objet d'une écriture permanente, la justice constitutionnelle qui en découle n'est pas non plus stabilisée.

$\mathrm{La}$ Cour suprême illustre ainsi l'alternative à laquelle le constitutionnalisme britannique semble faire face. Maintenir son particularisme en préservant une voie médiane à mi-chemin entre souveraineté parlementaire et suprématie constitutionnelle ${ }^{266}$ propice à un renouvellement de la notion de justice constitutionnelle ? S'engager, par l'abandon définitif du principe de souveraineté parlementaire, vers une suprématie de la Constitution telle que la garantissent certaines Cours suprêmes, au premier rang desquelles la Cour suprême américaine? Le statu quo prévaut pour le moment et la souveraineté reste «bi-polaire ${ }^{267}$, partagée entre le Parlement et les juges. L'un des deux pôles l'emportera-t-il ? On peut douter de l'abandon du principe juridique de souveraineté parlementaire dans un avenir proche, puisque le Parlement est aussi, dans le cadre de l'actuel régime parlementaire, le représentant du souverain politique qu'est le peuple. N'ayant pas été accompli par le $C R A$, simple révision constitutionnelle, le changement de nature de la Cour suprême nécessitera, en définitive, une véritable révolution constitutionnelle.

\footnotetext{
${ }^{264} \mathrm{H}$. KELSEN, «La garantie juridictionnelle de la Constitution (la justice constitutionnelle)», RDP, 1928, vol. 45, pp. 197-257.

${ }^{265} \mathrm{~L}$. Heushling indique d'ailleurs que «Le périmètre de la réalité contentieuse du droit constitutionnel est donc fonction du périmètre de la Constitution », in « Justice constitutionnelle et justice ordinaire. Epistémologie d'une distinction théorique », op. cit., p. 111.

${ }^{266}$ À ce propos, cf. Lord Laws International Transport Roth GmbH v. Home Secretary [2003] Q.B. $728 \S 71$.

${ }^{267}$ S. SEDLEY, «Human Rights : A Twenty-First Century Agenda », PL, 1995, p. 389 et C.J.S. Knights, « Bipolar Sovereignty restated », CLJ, 2009, pp. 368-387.
} 